\title{
Memorias de un ratón de hotel: delito, prensa y literatura en Brasil, 1890-1912
}

\section{Resumen}

Este artículo analiza las memorias de un célebre ladrón de hoteles del Brasil, publicadas como folletín del diario Gazeta de Notícias entre 1911 y 1912. En una primera parte, reconstruye, a partir de las crónicas policiales de la prensa y de procesos judiciales del Archivo Nacional, la trayectoria delictiva de ese ladrón, Arthur Antunes Maciel, más conocido como Dr. Antonio. En la segunda parte, intenta comprender la construcción de la narrativa de las memorias, como un proceso de negociaciones entre un repórter del diario, sus lectores y el proprio ladrón, detenido en la cárcel de Rio de Janeiro.

Palabras clave: Delito - Prensa - Literatura - Brasil

Memories of a hotel mouse: crime, newspapers and literature in Brazil, 1890-1912

\begin{abstract}
This article analyzes the memoirs of a famous brazilean hotel thief, published in the newspaper Gazeta de Notícias between 1911 and 1912. In the first part, this study reconstruct, based on the police chronicles of the press and the sources of the National Archive, the criminal trajectory of that thief, Arthur Antunes Maciel, better known as Dr. Antonio. In the second part, it tries to understand the narrative of the memoirs as a process of negotiation between a newspaper reporter, his readers and the thief arrested in the Rio de Janeiro's prison.
\end{abstract}

Key words: Crime - Press - Literature - Brazil 


\section{Introducción}

Literatura popular "vorazmente leída en la prisión, en los antros de vagabundaje, por hombres primitivos, murmurada a la luz de las lámparas de querosén en los caseríos humildes”. ${ }^{1}$ Así describía el cronista Paulo Barreto a los libros baratos que, a comienzos del siglo XX, se vendían como pan caliente en la entonces capital del Brasil, Río de Janeiro. Barreto era uno de los periodistas más importantes del moderno diario Gazeta de Notícias y firmaba con el seudónimo João do Rio la serie de crónicas urbanas en la que se inscribía este relato. Reunida más tarde en el libro El alma encantadora de las calles (1908), la serie era una apuesta narrativa que fusionaba recursos literarios con observación empírica de la vida en la ciudad, de la agitación de sus lugares de encuentro, de su sonoridad y rituales religiosos, de sus oficios informales y jergas que emergían de las conversaciones. El "temperamento etnográfico" de Barreto -según la expresión de Julia O’Donnell- es fundamental para entender la manera en que construía sus textos y que trababa un vínculo con sus fieles lectores. ${ }^{2}$

Los libros baratos, esos "folletos irreverentes de delitos y sandeces", contaba João do Rio, se habían convertido en el sustento cotidiano de vendedores ambulantes, cuyo número crecía en la proporción en que aumentaban sus consumidores. Aunque el tono de Barreto oscilaba aquí entre la burla y la condena, más tarde él mismo incursionaría en el mercado de la literatura policial para el gran público. Así sucedió con las Memorias de un ratón de hotel, publicadas entre diciembre de 1911 y febrero de 1912 como folletín de la Gazeta de Notícias, e inmediatamente después como un libro rústico y barato, muy vendido y comentado en la ciudad. El relato se presentaba como la autobiografía del “Dr. Antonio”, seudónimo de Arthur Antunes Maciel, un ladrón brasilero cuya fama fue edificada por la prensa entre finales del siglo XIX y comienzos del XX.

Muchos se preocuparon por demostrar la autoría de Barreto en ese libro de memorias del ladrón de hoteles. La búsqueda por el "verdadero autor" se acopla a una intención de definir los contornos difusos de la vasta obra del cronista. Como reconocía en la década de 1940 el memorialista Rubén Gill, la bibliografía de Barreto era

\footnotetext{
${ }^{1}$ Gazeta de Notícias, Río de Janeiro, 12 de febrero de 1906, p. 1, "Os mercadores de livros e a leitura das ruas" por João do Rio.

${ }^{2}$ O’DONNELL, Julia, De olho na rua. A cidade de João do Rio, Rio de Janeiro, Zahar, 2008, pp. 87-127.
} 
inconmensurable porque estaba plagada de escritos en la prensa firmados con seudónimos o inclusive sin mención de autor. Dentro de esta última categoría, incluía a las Memorias del Dr. Antonio.3 Lejos de la pregunta por la autoría, este artículo elije otro camino. Intenta reconstruir el modo en que una empresa como la Gazeta de Notícias, a través de uno de sus mejores periodistas, se acercó a un ladrón moribundo, lo convenció para que narrara su historia e inventó, así, un éxito editorial y un delincuente célebre. Para entender la cocina de ese proceso es fundamental no restringirse a las páginas del diario como fuente documental exclusiva. Puede leerse aquí una apuesta a la riqueza de la triangulación entre la obra literaria, las crónicas de la prensa escrita (no sólo la Gazeta de Notícias) y la documentación del archivo judicial.

Entre crónicas policiales, folletines, columnas literarias y anuncios publicitarios, el caso del Dr. Antonio permite discutir usos posibles de las fuentes periodísticas. Por un lado, se propone aquí una mirada sobre la prensa como documento para la historia social del delito, lo que abarca interrogantes por las condiciones de producción, circulación y recepción de los textos periodísticos, y por la forma en que la moderna prensa policial afectó la vida cotidiana de los ladrones, su relación con las autoridades y con la sociedad. Una historia del delito que considera, entonces, a la prensa como una fuente rica y legítima, al nivel del más clásico manantial de los archivos judiciales. En América Latina, la historiografía de la prensa y los estudios del delito en perspectiva histórica han tejido puntos de contacto, mostrando que algunos ladrones tenían injerencia concreta en la fabricación de los relatos que sobre ellos se publicaban.4 En ese sentido, la pregunta por la participación de Maciel en el proceso de construcción de sus memorias se torna aquí un punto de partida. El enigma de su testimonio, el problema de la voz del Dr. Antonio en un relato que se pretendía autobiográfico, no puede darse por cerrado por la constatación de la

\footnotetext{
${ }^{3}$ GILL, Rubén. "O Século Boêmio", Dom Casmurro, Nro. 318, Río de Janeiro, 11 de setiembre de 1943, p. 8. El periodista Joâo Carlos Rodrigues publicó un exhaustivo catálogo bibliográfico de los textos que Barreto publicó en la prensa y decidió incluir a las Memorias de un ratón de hotel como un "folletín sin firma" que formaba parte del opus João do Rio. RODRIGUES, João Carlos, João do Rio: catálogo bibliográfico, Río de Janeiro, Secretaria Municipal de Cultura, 1994, p. 14.

${ }^{4}$ Ver, por ejemplo: SAÍTTA, Sylvia, Regueros de tinta. El diario Crítica en la década de 1920, Buenos Aires, Sudamericana, 1998, pp. 189-220. CAIMARI, Lila, Apenas un delincuente. Crimen, castigo y cultura en la Argentina, 1880-1955, Buenos Aires: Siglo XXI, 2004, pp. 199-218. BUFFINGTON, Robert; PICCATO, Pablo, "Crime stories". In: BUFFINGTON, Robert; PICCATO, Pablo, True Stories of Crime in Modern Mexico, Albuquerque, University of New Mexico Press, 2009, p. 10-11.
} 
presencia de Barreto. La historia del encuentro entre el ladrón de hoteles y el repórter de la Gazeta de Notícias permite indagar en la compleja trama de la invención de su celebridad. Una historia hecha de madrugadas, hoteles, dinero, joyas y mucho papel de diario.

\section{Crónicas de un ladrón gentleman}

"Me llamo Arthur Antunes Maciel. Soy de la familia de los Maciel, familia riograndense. No me pregunten más. Tuve una vida de abundancia, sino de riqueza, desde que nací hasta los veinte años". ${ }^{5}$ Así resumía Dr. Antonio, en las Memorias de un ratón de hotel, sus primeras dos décadas de vida: la historia de una relación tensa con una poderosa familia de la ciudad de Pelotas, en el estado brasilero de Río Grande do Sul. Desde los tiempos del Imperio, los Antunes Maciel eran propietarios de títulos nobiliarios, cargos públicos y grandes extensiones de tierra. De acuerdo con el testimonio de las Memorias, Arthur no tenía mucho apego por la familia y pasaba su tiempo en prostíbulos. Esa situación generó un conflicto con el padre, que le fue limitando el acceso al dinero familiar, hasta que un día los amigos le mostraron a Arthur un recorte del diario A Federação. En el texto, el padre informaba a la ciudad que "no se responsabilizaba por ninguna deuda de Arthur Antunes Maciel, su hijo mayor". Ese fue el punto de partida de lo que Dr. Antonio denominó su "primer delito", un robo de títulos de propiedad de su padre que ejecutó estimulado por una banda de ladrones españoles, quienes se comprometieron a hipotecar el título. El padre descubrió el engaño y expulsó a Arthur de la casa, tratándolo de ladrón y acusándolo de haber deshonrado el nombre de la familia. "Caminé sin mirar atrás. No lo vi más. Y obedecí su orden: no volví nunca a Río Grande, nunca más vi a ningún pariente, perdí el nombre de la familia y la fortuna aquel mismo día" - recordaba Dr. Antonio en los últimos suspiros de su vida en la Casa de Detención de Río de Janeiro ${ }^{6}$.

\footnotetext{
${ }^{5}$ Dr. Antonio, Memórias de um rato de hotel. A vida de Dr. Antonio narrado por ele mesmo, Rio de Janeiro, 1912, p. 14. El libro no revela el año en que nació, pero en su primer proceso en la justicia criminal de Río de Janeiro (diciembre de 1891), Maciel declaraba tener 23 años, o sea que habría nacido alrededor de 1868. Jornal do Brasil, Río de Janeiro, 9 de diciembre de 1891, p. 3, "Jury". Esa fecha coincide con la información de que pasó sus primeros veinte años de vida en Río Grande do Sul y que habría huido hacia Río de Janeiro en noviembre de 1889. Dr. Antonio, Memórias, ob. cit., p. 28. En el proceso criminal de 1904, Arthur declaraba tener 38 años, lo que indicaría que puede haber nacido un poco antes, pero no mucho más allá de 1866.

${ }^{6}$ Dr. Antonio, Memórias, ob. cit., p. 20 y p. 25.
} 
No queda claro cuál de los Antunes Maciel era el padre del ladrón de hoteles. Hay al menos dos versiones diferentes. Por un lado, un interrogatorio en la sala de un juez del Tribunal Civil y Criminal ofrece una primera hipótesis. Arthur declara ser hijo de Leopoldo Antunes Maciel, nada menos que el Barón de São Luís, presidente interino de Río Grande do Sul en la década de 188o. En las Memorias, en cambio, aparece una información diferente. Según el relato, un cierto día en los comienzos de su carrera como ladrón de hoteles, cuando su "verdadero nombre" ya comenzaba a figurar en las páginas de la prensa, Dr. Antonio se encontraba detenido en una comisaría de Río de Janeiro. Un caballero alto y elegante pidió hablar con él, creyendo que se trataba de otro Arthur Antunes Maciel que conocía. Dr. Antonio explicó que ese homónimo era de un tío y que su padre era Francisco Antunes Maciel, hermano del Barón de São Luís y Ministro de los Negocios del Imperio. ${ }^{7}$

El hecho de que Arthur no aparezca en el árbol genealógico de la familia Antunes Maciel, ni como hijo de Leopoldo, ni como hijo de su hermano Francisco, es coherente con lo narrado en las Memorias. Dr. Antonio contaba que, en los días previos a su partida, ya expulsado de su casa paterna, un hombre que fue a buscar su maleta le trajo un recado del padre: "a la menor noticia que tuviera de mí en Río Grande, mis días estarían contados". Y también es coherente con su prontuario policial, adjunto al proceso de 1904 y elaborado por el Gabinete de Identificación de la policía de Río, en el que fue anotado como natural de la ciudad de Pelotas, sede de la poderosa familia Antunes Maciel8.

\footnotetext{
${ }^{7}$ Archivo Nacional de Brasil, Fondo Corte de Apelação, 1904, Proc. Nro.113, caja 1841, fls. 32-33 y Dr. Antonio, Memórias, ob. cit, p. 49.

${ }^{8}$ Archivo Nacional del Brasil, Fondo Corte de Apelação, Proc. Nro. 113, caixa 1841, 1904, fls. 56.
} 


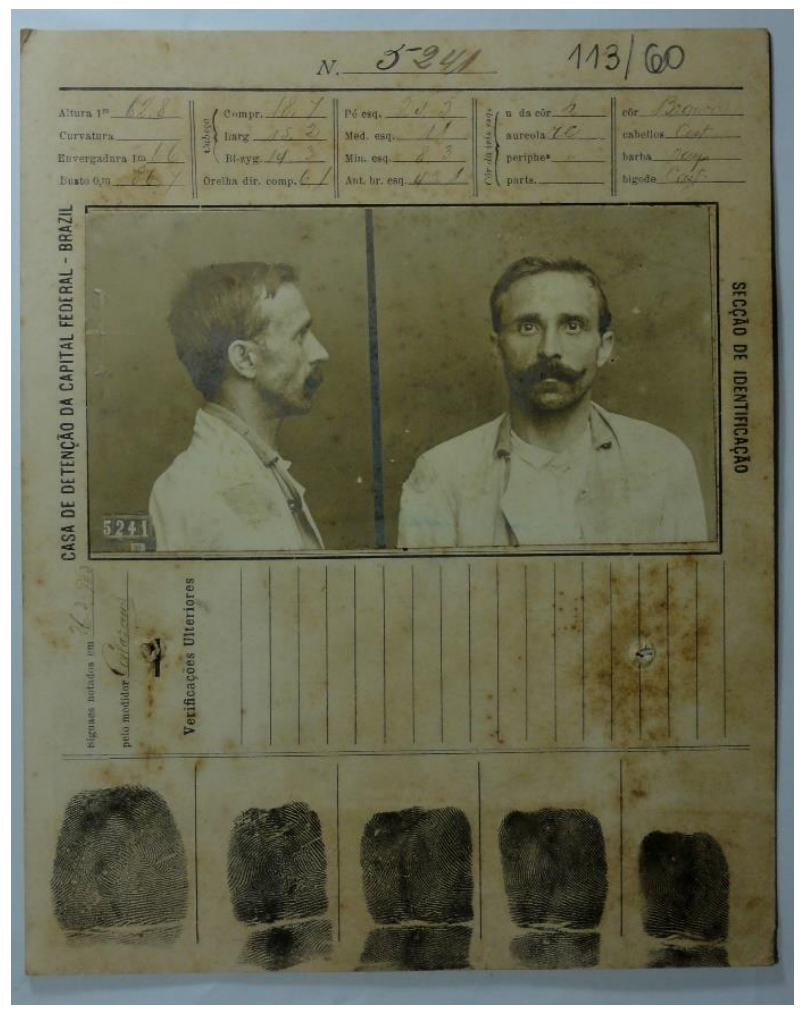

Imagen 1. Ficha de identificación de Arthur Antunes Maciel (Gabinete de Identificación de la Policía de Río de Janeiro). Fuente: Archivo Nacional de Brasil, Fondo Corte de Apelação, 1904, Proc. Nro. 113, caja 1841.

En el reverso de la ficha de identificación, además de la naturalidad y otros datos filiatorios, constaba el seudónimo que, en 1904, ya era bien conocido por la prensa carioca y muy probablemente por sus lectores: "Dr. Antonio". Ese apodo apareció después que Arthur migró de Río Grande a Río de Janeiro, en noviembre de 1889, el mismo mes que un golpe militar derrocó el gobierno imperial y proclamó el nuevo régimen republicano. Por eso se decía que "Dr. Antonio nació con la República". ${ }^{9}$ Los diarios de la época confirman que el seudónimo fue usado desde sus primeros robos en hoteles, ocurridos en octubre de 1890 en las ciudades de Río de Janeiro y Juiz de Fora. El primero tuvo lugar en el hotel Carsons de la calle Catete, en la madrugada del 25 de octubre. "Ayer a la mañana -narraba un cronista del Jornal do Comércio- dos huéspedes del Hotel Carsons denunciaron la falta de sus relojes y de $\$ 58$. Ambos dormían con la puerta abierta y el ladrón parece haber sido un viajante que llegó tarde,

\footnotetext{
${ }^{9}$ Dr. Antonio, Memórias, ob. cit., p. 28.
} 
anteayer a la noche, y se despidió ayer muy temprano”.10 En las Memorias, Arthur recordaba esos primeros vertiginosos robos de 1890:

\begin{abstract}
"Tomé un cuarto en el [Hotel] Victoria, otro en el [Hotel de los] Extranjeros, otro en el Internacional, otro en el Ville Moreau. Apenas en el Carsons utilicé el nombre de Dr. Antonio, nombre que no usé nunca más. En uno era Julio Doria, en otro Arthur Barcellos, en otro Antenor Guimarães. Y era un burgués rico en Niterói, donde me hice socio de una sastrería en la calle del Emperador". ${ }^{11}$
\end{abstract}

La documentación policial y las crónicas de la prensa dan cuenta de esos múltiples nombres usados por Arthur: "veinte hombres en un solo hombre", según la expresión que le daba título a un capítulo del libro. Pero, a su vez, contradicen el recuerdo de no haber usado más el seudónimo Dr. Antonio. De hecho, el rastreo de su itinerario en las crónicas policiales de la prensa revela que el ladrón de hoteles, después de abandonar el Carsons, siguió camino rumbo a Juiz de Fora y se instaló en el Hotel Río de Janeiro, donde firmó el libro de huéspedes con el nombre "Dr. Antonio Arthur Maciel". De acuerdo con las crónicas, llegó al hotel "trajeado con elegancia y excentricidad, usando en el dedo índice de la mano izquierda un anillo de médico"12. Al parecer, no logró robar nada porque el gerente del hotel desconfió de su presencia e informó a la policía local, que a su vez telegrafió a la jefatura de policía de Río. Esa red de sospechas, sin delito cometido, motivó que en las Memorias Arthur recordara el incidente como un caso típico de "desconfianza minera", rasgo que la cultura popular brasilera le atribuye a los nativos del estado de Minas Gerais. Dr. Antonio fue detenido en un calabozo, a la espera de dos agentes policiales que lo buscarían para llevarlo de nuevo a Río de Janeiro, para ser juzgado por el robo en el Carsons. Antes de la partida, fue interrogado por la policía de Juiz de Fora, que encontró en su poder objetos de oro, piedras preciosas e un cincel. ${ }^{13}$

En Río, entró por primera vez en el "inenarrable infierno de inmundicia y crimen sórdido", como llamaba en las Memorias a la Casa de Detención de la Capital

\footnotetext{
${ }^{10}$ Jornal do Comércio, Río de Janeiro, 25 de octubre de 1890, p. 1, "Furto".

${ }^{11}$ Dr. Antonio, Memórias, ob. cit., p. 31.

${ }^{12}$ Diário de Notícias, Río de Janeiro, 29 de octubre de 1890, p. 1, "Dr. Frotzmack".

${ }^{13}$ Cidade do Rio, Río de Janeiro, 28 de octubre de 1890, p. 1 y O Cruzeiro. Orgão do Partido Catholico, Río de Janeiro, 29 de octubre de 1890, p. 1, "Estado de Minhas".
} 
Federal. ${ }^{14}$ Esta vez, apenas pasó un mes en la prisión que más tarde consumiría varios años de su vida: allí conocería muchos de los más célebres delincuentes cariocas y periodistas de su época, allí se entrevistaría con Paulo Barreto y produciría -junto con el repórter- su autobiografía y allí, además, moriría poco después de publicada su última entrega. El propietario y el conserje del Carsons fueron a reconocerlo a la Casa de Detención. De la cárcel salió rápido pero con el nombre sucio, expuesto en las páginas del Jornal do Comércio, Diário de Notícias, Cidade do Rio y O Cruzeiro ${ }^{15}$. "Desde que los diarios hablaron, llevando mi nombre a la fantasía de los reporters, desde que los agentes me miraron y aconsejaron conseguirme un abogado, metí el pie en el terrible engranaje del que jamás se sale”, recordaba con nostalgia en el ocaso de su vida ${ }^{16}$.

"Salí de la prisión humillado. Me metí en el Hotel Macedo, en la calle del Areal, un hotel frecuentado por gente del interior, por senadores miserables, por viejas momias"17. Eran los años del Encilhamento, como se le llamó en la entonces capital brasileira al momento de fiebre especulativa de la crisis del 1890. La denuncia a la codicia y al arribismo desenfrenado ocupaba las tapas de los diarios. Así, los robos y el estilo de vida de Arthur Antunes Maciel estaban a tono con el paisaje urbano descrito por el Visconde de Taunay: "la sed de riqueza, las ansias del lujo, de la posesión, del desperdicio, de la ostentación, del triunfo, todo eso de prisa, muy de prisa, de un día para el otro"18. Por eso decía Dr. Antonio: "solo en una ciudad como Río podía pasar desapercibido un hombre gastando lo que yo gastaba, en autos, hoteles, mujeres y teatros"; solamente en el Río de Janeiro del Encilhamento, donde "los cocheros y los coperos amanecían millonarios" 19 .

\footnotetext{
${ }^{14}$ Dr. Antonio, Memórias, ob. cit., p. 48. Sobre la Casa de Detención de Río de Janeiro ver: CHAZKEL, Amy, "Uma perigosíssima lição: a Casa de Detenção do Rio de Janeiro na Primeira República". In: MAIA, Clarissa Nunes; NETO, Flávio de Sá; COSTA, Marcos y BRETAS, Marcos Luiz (orgs), História das Prisões no Brasil, Vol. 2, Rio de Janeiro, Rocco, 2009.

${ }^{15}$ Jornal do Comércio, Río de Janeiro, 30 de octubre de 1890, p. 1, "Falso doutor e gatuno"; Diário de Notícias, Río de Janeiro, 30 de octubre de 1890, p.1,"Dr. Frotzmack"y O Cruzeiro. Orgão do Partido Catholico, Río de Janeiro, 30 de octubre de 1890, p. 2, "Falso doutor".

${ }^{16}$ Dr. Antonio, Memórias, ob. cit., p. 37.

${ }^{17}$ Dr. Antonio, Memórias, ob. cit., p. 48.

${ }^{18}$ TAUNAY, Visconde de, O Encilhamento: cenas contemporâneas da Bolsa do Rio de Janeiro em 1890, 1891 e 1892, San Pablo, Melhoramentos, 1923, p. 17.

${ }^{19}$ Dr. Antonio, Memórias, ob. cit., p. 35.
} 
Tal vez fue por eso que siempre volvió a la capital, a pesar de que muchas veces se veía en la obligación de huir por un tiempo: Minas Gerais, San Pablo y Bahía fueron sus destinos provisorios cuando la vigilancia y la persecución de los policías entorpecían su hedonista vida carioca. De hecho, las detenciones en los calabozos policiales fueron mucho más frecuentes que las condenas efectivas en la justicia. $\mathrm{Su}$ primer encuentro con un tribunal fue en diciembre de 1891, por un robo de abril de ese año. En este caso fue juzgado por un jurado popular: acudieron 37 jurados y Arthur Antunes Maciel fue absuelto por ocho votos ${ }^{20}$. Apenas un mes después, al ser detenido por un robo en el Hotel Freitas, del barrio de Lapa, la prensa carioca ya trataba a Dr. Antonio como un "ladrón célebre"21.

Entre 1892 y 1895 una serie de robos protagonizados por Maciel inundaron las páginas de los diarios brasileros. Entre la prensa y las Memorias es posible reconstruir una primera nómina de los hoteles que eligió para hospedarse y robar: Hotel de los Extranjeros, Hotel del Comercio, Gran Hotel Internacional, Giorelli, Carsons, Ville Moreau, Vista-Alegre, Freitas y Santa Teresa. "En todos esos hoteles -según las Memorias - tenía una maleta con ropas y un nombre diferente" ${ }^{22}$. En la primera década republicana, la Capital Federal del Brasil ofrecía a Maciel un amplio campo de posibilidades en materia hotelera, en una industria que crecía permanentemente, hospedando un contingente cada vez mayor de empresarios, jueces, médicos, diputados, senadores y artistas. En 1890, cuando comenzó sus actividades delictivas, Río de Janeiro contaba con cerca de 130 establecimientos hoteleros, mientras que hacia el final de la década la cifra había ascendido a $235^{23}$.

En el libro de huéspedes del Hotel Freitas se registró como un juez, pero eso no impidió que recayeran sobre él las sospechas por la desaparición de un reloj, una cadena de oro y la suma de trecientos mil reis ${ }^{24}$. El robo fue en la noche del 21 de enero.

\footnotetext{
${ }^{20}$ Gazeta de Notícias, Río de Janeiro, 5 de diciembre de 1891, p. 2, “Jury” y Jornal do Brasil, Río de Janeiro, 9 de diciembre de1891, p. 3, "Jury".

${ }^{21}$ La frase "célebre gatuno" (ladrón célebre) aparece en una crónica policial -sin título- del diario O Combate, Río de Janeiro, 23 de enero de 1892, p. 1 y también en Jornal do Comércio, Río de Janeiro, 23 de enero de 1892 , p. 2, "Roubo em um hotel".

${ }^{22}$ Dr. Antonio, Memórias, ob. cit., p. 32.

${ }^{23}$ Almanak Laemmert. Administrativo, mercantil e industrial do Rio de Janeiro para 1889, Río de Janeiro, Laemmert \& C., 1889, pp. 730-737 y Almanak Laemmert. Administrativo, mercantil e industrial do Rio de Janeiro para 1897, Río de Janeiro, Comp. Typ. do Brasil, 1897, pp. 502-505.

${ }^{24}$ Diário do Comércio, Río de Janeiro, 23 ene. 1892, p. 2, "Crônica da ladroeira”.
} 
Cuando al día siguiente se descubrió, Maciel ya no estaba en el hotel. El dueño hizo la denuncia ante el $1^{\circ}$ Delegado Auxiliar (autoridad de la policía de investigaciones), quien esperó al ladrón en el hotel para detenerlo. Es probable que Maciel haya aprovechado esa salida para dejar el dinero y los objetos robados en otro de los hoteles en los que estaba hospedado. Cuando lo detuvieron encontraron en su poder diversos valores (una bolsa de joyas en plata, una medalla con brillantes, dos relojes), pero ninguno coincidía con lo que se buscaba. Maciel negó ser el autor de los hechos y, ante la falta de pruebas, fue liberado por orden judicial. Esa dinámica se repetiría una y otra vez: considerado culpable por hoteleros, periodistas y policías, el principio de presunción de inocencia lo devolvía rápidamente a la calle. Sin embargo, aunque no lo llevara a la cárcel, esa dinámica roía de a poco su escaso capital social.

Pocos días después, en el mismo verano de 1892, fue acusado de otro robo en el Hotel Giorelli. Según las crónicas policiales de la prensa, estaba hospedado con el nombre de Antonio Barcellos y lo detuvieron en los pasillos del hotel mientras intentaba ingresar a una de las habitaciones. Además de cazarlo infraganti, encontraron entre sus pertenencias dinero, relojes, corrientes, medallas de oro y objetos de valor del propio hotel. El cronista del Diário do Comércio decía que Dr. Antonio iba preso por "millonésima vez" y el de la Gazeta de Notícias que "tenía tantas entradas en la Casa de Detención como años de edad". Estos periodistas pedían que la policía mandara a poner su retrato en todos los hoteles para "prevenir a los incautos". 25 En las Memorias, Dr. Antonio se refería a las "noticias escandalosas" que se publicaron tras el robo en el Giorelli y les atribuía gran parte de la responsabilidad de haberlo enviado a la Casa de Detención. De acuerdo con su relato, la detención no fue en el hotel ni en flagrante delito, sino en la calle del Sacramento y por "simples sospechas". Denunciaba que una alianza entre periodistas, agentes policiales y comisarios era responsable de inventar pruebas inexistentes y atribuirle robos que no había cometido ${ }^{26}$.

La versión de los hechos que el Delegado Auxiliar elevó al juez de la causa difería de los recuerdos que una década más tarde se plasmaban en la escritura autobiográfica. El informe policial reafirma que había sido detenido dentro del hotel y de madrugada

\footnotetext{
${ }^{25}$ Diário do Comércio, Río de Janeiro, 6 de febrero de1892, p. 1, “O. Dr. Antonio y Gazeta de Notícias, Río de Janeiro, 7 de febrero de1892, p. 1, "Gatunos e gatunices".

${ }^{26}$ Dr. Antonio, Memórias, ob. cit., p. 73.
} 
cuando, "desnudo de la cintura para arriba y descalzo", trataba de forzar un armario después de haber intentado, sin éxito, entrar en diversas habitaciones. La policía reforzaba su "auto de flagrante" con otros datos que construían la imagen de un ladrón reincidente en el mismo delito: "ladrón muy conocido de la policía de esta Capital Federal y de la de San Pablo", donde también estaba fichado²7.

En los diez años que pasaron desde su detención de 1892 hasta su muerte en 1912, la vida de Dr. Antonio se tornó un constante entrar y salir de la cárcel de Río de Janeiro, con algunos pasos por los tribunales del crimen. Algunos meses después de la prisión por el robo en el Hotel Giorelli, recuperó la libertad y su rastro se perdió de la prensa por un tiempo. Lo que nos queda de ese tramo de su vida es la versión del folletín: con los pies en la calle Lavradio, Maciel tomó un coche de alquiler y pidió al chofer que lo llevara hasta el Hotel Ville Moreau, en el barrio de Tijuca, alejándose así de la zona céntrica y de los barrios contiguos de Catete, Lapa y Santa Teresa, escenario de sus primeros robos. Llegó al hotel al anochecer y se hospedó en la habitación 22, pagando por anticipado una semana de hospedaje. Según el relato, ante el primer robo en el hotel terminó en la comisaría, pero por la falta de pruebas el comisario lo liberó, no sin antes advertirle que la policía carioca jamás le sacaría el ojo de encima. Por eso habría decidido abandonar Río de Janeiro por un tiempo.

Compró un pasaje de un vapor rumbo a Salvador, donde habría robado en hoteles usando el nombre de Julio Doria. La policía bahiana lo detuvo y, con las informaciones que la policía de Río le envió por vía telegráfica, pudo saber que Doria era el célebre Dr. Antonio. Maciel pudo escaparse de la prisión por la ayuda de un agente policial y embarcó rumbo a San Pablo. Decidió entonces cambiar el nombre y pasó a llamarse Arthur Macedo, pero de nuevo la cooperación policial entre los servicios de identificación del Brasil lo desenmascararon. Pasó tres meses en una prisión de la ciudad de San Carlos do Pinhal y, al salir, volvió a Río de Janeiro ${ }^{28}$. En este punto del relato, las Memorias se contradicen con las crónicas policiales de la prensa. De acuerdo con el folletín, al regresar de San Pablo se hospedó en el Hotel Vista Alegre del barrio de Santa Teresa. El paso por ese lugar existió, pero no sucedió a la

\footnotetext{
${ }^{27}$ El informe que el Delegado Auxiliar, Santiago Silva, remitió al juez fue reproducido por algunos diarios: $O$ Combate, Río de Janeiro, 11 de febrero de 1892, p. 1, "Gatuno" y Gazeta da Tarde, Río de Janeiro, 11 de febrero de 1892, p. 1, "O Dr. Antonio".

${ }^{28}$ Dr. Antonio, Memórias, ob. cit., pp. 111-121.
} 
vuelta de un viaje sino a la salida de la Casa de Detención de Río de Janeiro, en septiembre de 1895, gracias a un recurso de habeas corpus. Cruzando fuentes judiciales del Archivo Nacional con crónicas de la prensa es posible captar algo del carácter agitado de esos días de Dr. Antonio. El 26 de agosto de 1895, la Corte de Apelaciones recibió en manos del abogado Julio do Valle un pedido de habeas corpus para obtener la libertad de Maciel. Según el manuscrito, su prisión por orden de la jefatura de policía era ilegal porque no había sido acompañada de un pedido del juez ni de sumario de flagrante delito ${ }^{29}$.

Al día siguiente, el presidente de la Corte de Apelaciones enviaba a la Casa de Detención una orden de liberación de Maciel, pidiendo que el preso se presentara en el juzgado el martes 3 de setiembre para ser notificado. Una nota de la Casa de Detención, también adjunta al proceso, confirma que Maciel se presentó ese día y quedó en libertad ${ }^{30}$. Si el martes Dr. Antonio estaba en las páginas judiciales de los diarios por la noticia del habeas corpus, el sábado de la misma semana ya daba un salto veloz a las crónicas policiales. Es que apenas cuatro días después de su liberación, caía de nuevo por un robo en el Hotel Vista Alegre, en el morro de Santa Teresa, que se jactaba que ser el primer "gran hotel de los arrabales de la ciudad". El propietario comunicó a la policía de investigaciones que en la noche del 4 al 5 de septiembre (es decir tan solo un día después de la audiencia en la Corte de Apelación) el Barón de Monte Castello, distinguido huésped del establecimiento, había caído en las garras del Dr. Antonio, también hospedado en el lugar con el nombre de Arthur Prado. Desapareció en seguida del hotel, llevándose diversas joyas y una altísima suma de dinero que pertenecían al Barón. Agentes lo detuvieron el día 10 en una barbearía de la Plaza Tiradentes y pudieron recuperar algunas joyas del Barón, que estaban distribuidas en tres orfebrerías del centro de la ciudad. Sin flagrante delito, ni pruebas en su poder, Maciel fue liberado rápidamente. ${ }^{31}$

\footnotetext{
${ }^{29}$ Archivo Nacional de Brasil, Fondo Corte de Apelação, 1895, Proc. Nro. 199, caja 1, "Conselho Supremo da Corte de Apelação - Habeas corpus Nro. 857 - Arthur Antunes Maciel", fls. 2-4.

${ }^{30}$ Ídem, Ofício do Presidente da Corte de Apelação (27 de agosto de 1895) y Ofício da Casa de Detenção do Distrito Federal (3 de setiembre de 1895), fls. 7-10. Sobre su liberación ver también: Jornal do Brasil, Río de Janeiro, 5 de setiembre de. 1895, p. 3, "Secção forense".

${ }^{31}$ Gazeta de Notícias, Río de Janeiro, 7 sep. 1895, p. 2, "Hotel Vista Alegre”.y Gazeta da Tarde, Río de Janeiro, 10 de setiembre de 1895, p. 1,"O Dr. Antonio".
} 
"El conocido y audaz ladrón Antunes Maciel, vulgo Dr. Antonio, fue puesto ayer en libertad: icuidado con él!" - se leía en una crónica de la Gazeta da Tarde ${ }^{32}$. Ante la imposibilidad de enviarlo de nuevo a prisión, la prensa capitalina se movilizó para advertir a sus lectores, hoteleros y huéspedes: el temible Dr. Antonio andaba suelto en la calle. Es probable que el desprecio por los agentes de la policía de investigaciones (o “secretas") y el rencor con los reporteros de los diarios, que atraviesan por igual las páginas de las Memorias, hayan sido sentimientos que Paulo Barreto observó en su entrevista con el ladrón y que decidió privilegiar en la narrativa del folletín. Lo cierto es que la policía y la prensa se convirtieron, a partir de este momento, en sus enemigos aliados. El jefe de policía mandó a colocar en los hoteles un cuadro con los retratos fotográficos de los ladrones que frecuentaban esos establecimientos y la prensa difundía noticias sobre sus posibles destinos33.

"Los diarios, atendiendo a que no hay semana en que Dr. Antonio no sea preso y puesto en libertad, abrieron contra él una campaña terrible”, escribía en una de sus crónicas Olavo Bilac, quien poco tiempo después se consagraría como el más importante poeta brasilero.34 Esa crónica fue publicada a fines de octubre de 1895, a propósito de una nueva detención de Maciel. Esta vez el robo fue en el Gran Hotel del barrio de Lapa, cerca del Hotel Freitas. El informe que la policía de investigaciones elevó al Juez de la $4^{\circ}$ Pretoría de Río de Janeiro revela detalles del episodio delictivo y del modus operandi de Dr. Antonio:

\begin{abstract}
"En el día 8 de octubre, el conocido y reincidente ladrón Arthur Antunes Maciel se hospedó en el Gran Hotel del Largo da Lapa, dando el nombre de Julio de Vasconcelos y la profesión de ingeniero, artificio del que ya muchas veces se ha valido para captar la confianza de los propietarios y huéspedes de grandes hoteles donde ha cometido robos y hurtos. En la madrugada del día 9, Arthur Maciel, logrando penetrar en los aposentos del Dr. Raúl Rezende de Carvalho, substrajo diversas joyas y dinero y, en seguida, al salir del hotel, fue a la casa de negocios de Antonio dos Santos Rangel, en la calle Frei Caneca Nro. 374, donde dejó guardado los objetos robados" 35 .
\end{abstract}

\footnotetext{
${ }^{32}$ Gazeta da Tarde, Río de Janeiro, 29 de setiembre de1895, p. 1, "O Dr. Antonio".

${ }^{33}$ Jornal do Comércio, Río de Janeiro, 12 de setiembre de 1895, p. 2, "Ladrões e gatunos".

${ }^{34}$ A Cigarra, año I, Nro. 24, Río de Janeiro, 17 de octubre 1895, p. 2, “Chronica” por Fantasio [Olavo Bilac].

${ }^{35} \mathrm{El}$ informe del $2^{\circ}$ Delegado Auxiliar, Dr. Lafayette das Chagas, fue reproducido íntegramente en: Jornal do Comércio, Río de Janeiro, 26 de octubre de 1895, p. 1,"Roubo de joias".
} 
En su declaración testimonial, Maciel admitió haberse hospedado en el hotel con nombre falso e intenciones delictivas, pero negó ser el autor del robo que se le imputaba. Esta vez, el juez lo dejó detenido y el caso terminó de nuevo en los tribunales del jury popular. En realidad, hubo dos juicios diferentes. El primero, en junio de 1896, volvía sobre el robo en el Hotel Giorelli de febrero de 1892, por el que Maciel había sido excarcelado después de pagar fianza. Fue condenado, por los 45 jurados presentes, a cinco años y cuatro meses de prisión. ${ }^{36} \mathrm{El}$ segundo fue en agosto de 1896, por el robo en el Gran Hotel de Lapa. La sesión fue abierta con 37 jurados presentes, y Maciel fue nuevamente condenado, en este caso a tres años de prisión. La defensa del acusado apeló, pero en febrero de 1897 la Corte negó el recurso y confirmó la condena.37 Dr. Antonio pasó, de esta manera, de la Casa de Detención a la de Corrección.

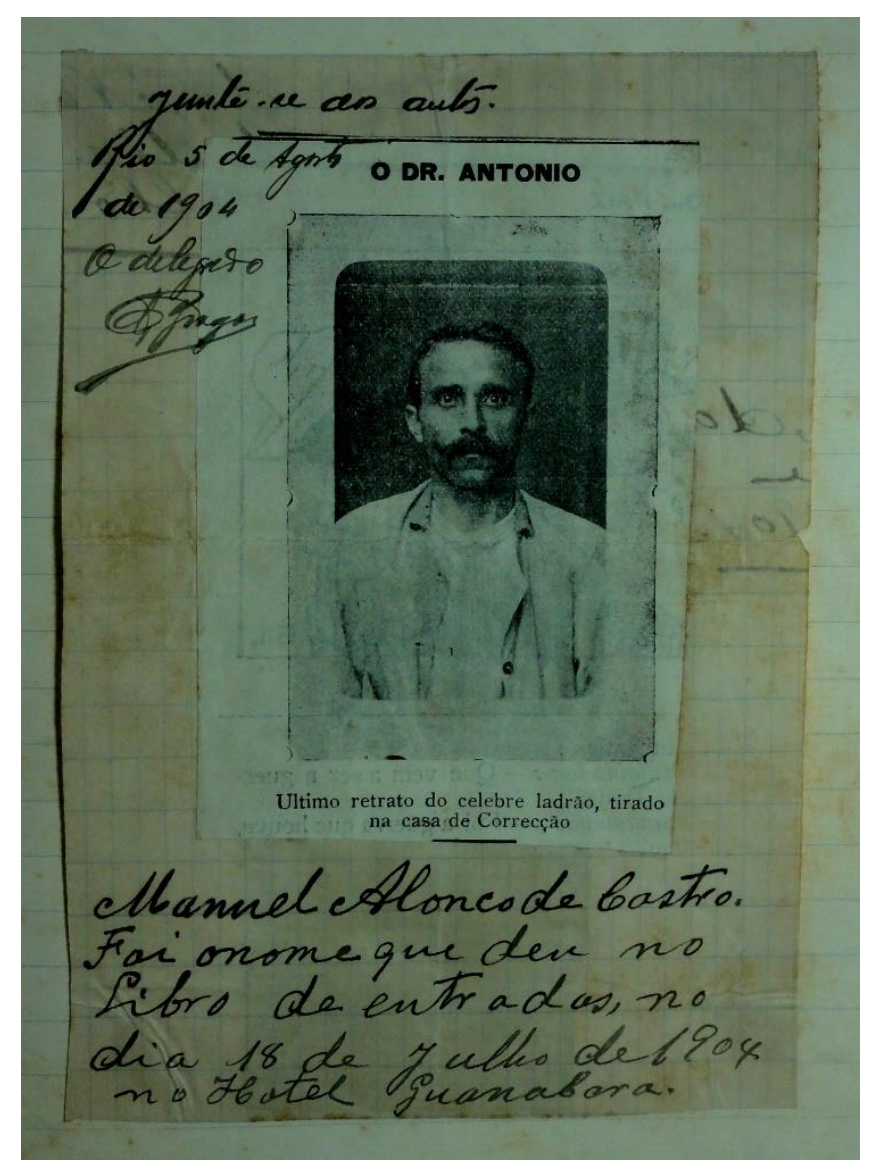

Imagen 2. Retrato de Dr. Antonio publicado en prensa con anotaciones del $2^{\circ}$ Delegado Auxiliar de la Policía de Río de Janeiro. Fuente: Archivo Nacional de Brasil, Fondo Corte de Apelación, 1904, Proc. Nro. 113, caja 1841.

\footnotetext{
36 “Jornal do Brasil, Río de Janeiro, 17 de junio 1896, p. 3, "Jury”; Cidade do Rio, Río de Janeiro, 18 de junio de 1896, p. 2, "Tribunais", y O Paiz, Río de Janeiro, 18 de junio de 1896, p. 2“Tribunais".

${ }^{37}$ Cidade do Rio, Río de Janeiro, 12 ago. 1896, p. 2, "Jury”; Jornal do Brasil, Río de Janeiro, 13 ago. 1896, "Jury", p. 4 y $O$ Paiz, Río de Janeiro, 20 de febrero de 1897, p. 2, "Corte de Appelação".
} 
Las Memorias no exageraban cuando decían que, en comparación con las noticias de los robos, la prensa trataba a los juicios con discreción, relegados a las grises y lacónicas columnas de actualidad de los tribunales. "Mi juicio" - exclamaba la voz de Dr. Antonio - "no fue nada sensacional” y, según su visión, la inexistencia de pruebas poco importó ante la "creencia popular que me consideraba el único ratón de hotel". ${ }^{8} 8$ Como se le sumaron las dos condenas, pasó ocho largos años en la Casa de Corrección, de la que recién salió en 1904. Pero ya no estaría mucho tiempo en libertad. Entre julio y agosto de 1904 se hospedó en el Hotel Guanabara con el nombre de Manuel de Castro y con el nombre de Arthur Braga en el Gran Hotel Belo Horizonte, ambos en Río de Janeiro.

Las crónicas de la prensa muestran que la coartada de los nombres falsos le resultaba cada vez menos eficaz. Aunque llegó a robar joyas, relojes de oro y cadenas de plata, el dueño del Hotel Belo Horizonte lo reconoció como el "célebre Dr. Antonio" e hizo la denuncia a la policía. Fue detenido el 15 de agosto en la puerta de una hostería céntrica y confesó que había empeñado las joyas en la Casa Cahen. Fue condenado por un tribunal criminal y el recurso de habeas corpus, esta vez, no sirvió de nada. Volvió a la Casa de Detención, a la que ingresó vistiendo un frac negro, camisa blanca y sombrero el 17 de setiembre de 190439. En el último capítulo de las Memorias, contaba resignado, y en forma escueta, la sucesión de acontecimientos que vinieron después de la prisión de 1904:

"Fui condenado a tres años y medio. Salí en 1908. Estuve apenas cuatro meses suelto, porque en seguida descubrieron que le substraje la billetera a un abogado de Pará con la cuantía de $\$ 900$ [...]. Acababa de cumplir la pena en 1911 cuando fui de nuevo preso por un crimen que no cometí. Es la persecución definitiva. Es la sociedad armada en su estupidez contra un hombre inteligente, que, sin un arma, sin nunca haber usado un revólver, sin nunca haber herido a nadie, mostró cómo podía vaciar al burgués feliz sin caer infraganti.

\footnotetext{
${ }^{38}$ Dr. Antonio, Memórias, ob. cit., p. 91.

${ }^{39}$ Archivo Nacional de Brasil, Fondo Corte de Apelação, 1904, Proc. Nro. 113, caja 1841, fls. 3-30 y Jornal do Brasil, Río de Janeiro, 17 de agosto de 1904, p. 2, "O Dr. Antonio".
} 
[...] Inicié en Brasil el robo fino, el robo gentleman, de guantes de seda y buenas ropas. [...]

Fui el primer impuesto de la civilización, el parásito del lujo40"

Este alegato final del folletín, con su idealización de un ladrón glamoroso, reflejaba mucho más las intenciones de Barreto que la voz de Maciel. De todos modos, sería un error interpretar a las Memorias como un mero producto de la imaginación inagotable del repórter carioca. El entrecruzamiento de fuentes periodísticas, judiciales y policiales con el texto del propio folletín revela que Barreto, después de entrevistar al ladrón de hoteles en la Casa de Corrección, se preocupó por producir un reportaje verosímil. Muchas veces la historia contada por el folletín se alejaba de los acontecimientos narrados por la prensa, por los policías y por los testigos. Es difícil determinar, en cada caso, si la diferencia provino de lo que Maciel pudo y quiso contar, o de lo que Barreto prefirió relatar, de la manera en que tomó decisiones narrativas y estéticas, ejecutó recortes e, inclusive, añadió elementos nuevos. Pero es necesario leer a las Memorias como el producto de la negociación entre todos esos factores, más que de la pura invención especulativa del repórter. $Y$ en esa negociación la experiencia del ladrón de hoteles, su punto de vista y su voz, estaban presentes.

\section{La metamorfosis en rat d'hôtel}

Domingo 10 de noviembre de 1907. Como todos los días, la Gazeta de Notícias abría espacio en sus columnas a diversas calamidades, delitos y novedades policiales. Ícono de la prensa moderna brasilera, este diario desplegaba todas las estrategias posibles de captación de lectores: distribución de ejemplares en la calle con vendedores gritando a viva voz las noticias, columnas especializadas en diversos temas de interés del gran público y literatura en folletín ${ }^{41}$. La tapa de ese día mostraba una dramática ilustración sobre las inundaciones en Málaga. En la página siguiente los lectores encontraban un largo reportaje sobre el funcionamiento del Gabinete de Identificación de la policía carioca. En la tercera, un folletín de Maurice Leblanc: Arsênio Lupin, cavalheiro ladrão. Se trataba del capítulo sobre la evasión de la cárcel, publicado originalmente en el magazine francés Je sais tout, el 15 de enero de 1906. El notable éxito de esa serie llevó a la editorial Pierre Lafitte a reunir los nueve primeros relatos

\footnotetext{
${ }^{40}$ Dr. Antonio, Memórias, ob. cit., p. 175-176.

${ }^{41}$ BARBOSA, Marialva, História cultural da imprensa Brasil, 1900-2000, Río de Janeiro, Mauad, 2007, pp; 4148. PEREIRA, Leonardo, "Negociações impressas: a imprensa comercial e o lazer dos trabalhadores no Rio de Janeiro da Primeira República”. Revista História, San Pablo, UNESP, Vol. 35, 2016.
} 
en el libro Arsène Lupin, gentleman-cambrioleur (1907), que rápidamente circuló por el mundo en diversas traducciones. Había algo en ese ladrón gentleman, en aquel caballero inteligente, "hombre de los mil disfraces", que encantaba a los lectores de la prensa moderna, mucho más allá de las fronteras de Francia42.

Cerca de la traducción de Lupin, en ese mismo número de la Gazeta de Notícias aparecía una crónica firmada con las iniciales O.B.43 Su autor era Olavo Bilac, uno de los colaboradores más importantes del periódico junto a Machado de Assis. En sus relatos sobre el día a día de la ciudad de Río, Bilac incluía frecuentes críticas irónicas acerca de la acción e inacción de la policía carioca. La entonces Policía de la Capital Federal estaba siendo -según el cronista- ampliamente superada en astucia por un nuevo tipo de ladrón "civilizado" que era, en sí mismo, fruto de la propia civilización y del progreso. Bilac comenzaba relativizando esa realidad de los delincuentes gentleman y polemizando con el éxito del autor francés cuyo folletín aparecía en las páginas del mismo diario:

\begin{abstract}
"En general todos los delincuentes son imbéciles. En el noventa y cinco por ciento de los crímenes que se cometen, la captura y el castigo de los delincuentes se deben a su propia estupidez y no a la agudeza de la policía. Los Arsenio Lupin son héroes de novela, son ficciones. Y ya el gran Fouché (que de eso sabía como nadie) solía decir que si los malhechores no fueran tontos, la justicia estaría perdida..." 44
\end{abstract}

Pese a darle la razón al mítico policía francés Joseph Fouché, Bilac dedicaba el resto de la crónica a ese minúsculo cinco por ciento de ladrones inteligentes que crecían en Río de Janeiro, presentándose como “caballeros de la más fina sociedad”. Durante esos primeros días de noviembre de 1907 los diarios cariocas hablaban de una "delicada banda de vivarachos", que los periodistas bautizaron "cofradía de los chicos bonitos". La gran dificultad que la policía enfrentaba a la hora de combatir esta cuadrilla estaba cifrada en su nombre: no era fácil desmontarla porque "para eso sería

\footnotetext{
${ }^{42}$ La traducción de la Gazeta de Notícias "Arsénio Lupin, cavalheiro-ladrão" era -en lo que se refiere al títulomás próxima del original en francés que las traducciones posteriores al portugués: LEBLANC, Maurice. Arsênio Lupin, ladrão de casaca. Trad. João Távora. Río de Janeiro: Casa Editora Vecchi, 1952. Sobre Arsène Lupin y los delincuentes gentleman en el romance policial francés, ver: KALIFA, Dominique, L'encre et le sang. Récits et société à la Belle Époque, Paris, Fayard, 1995, pp. 219-222.

${ }^{43}$ Gazeta de Notícias, Río de Janeiro, 10 de noviembre de1907, p. 5, "Chronica" por O.B. Este texto fue reproducido en: BILAC, Olavo, "Crônica. 10 de noviembre de 1907", In: DIMAS, Antonio (ed.), Bilac, o Jornalista. Crônicas. Vol. I, San Pablo, Edusp/Unicamp, 2006, pp. 848-851.

${ }^{44}$ Gazeta de Notícias, ob. cit., p. 5, "Chronica" por O.B.
} 
necesario distinguirla y separarla de la gente de la buena sociedad, con la cual por artes diabólicas se mezcló". 45 Como Arsène Lupin, los mozos bonitos eran muchachos simpáticos, elegantes, bien vestidos y gastaban mucho dinero en los circuitos de entretenimiento de la ciudad. Eran, como escribía un periodista, "los apaches de nuestra civilización” 46 .

Para Bilac, más que de la civilización, se trataba de la "hiper-civilización" del consumo. La idea del ladrón gentleman es fundamental para entender la construcción de la figura del delincuente célebre en la sociedad carioca de comienzos del siglo XX. ¿Tendría algún día el país un delincuente digno de la fama de Jack the Ripper o de Jean-Bapiste Troppmann? - se preguntaban los periodistas brasileros. Acaso pocos se involucraron tanto con esa cuestión como Paulo Barreto desde sus columnas firmadas con el seudónimo de “João do Rio”. En las páginas del diario A Notícia, publicó varias intervenciones que apuntaban a discutir las condiciones de posibilidad de una delincuencia célebre nacional. En septiembre de 1909, cuando todavía estaban frescas en la memoria las noticias sobre la cofradía, el espacio del folletín albergó un relato de João do Rio sobre un chico bonito que parecía frustrado por las dificultades para ser un verdadero delincuente gentleman en ese país. El muchacho se quejaba por la mala suerte de no estar en Francia, de vivir en un país "que de hidalguía solo tiene la voluntad snob". En la definición que João do Rio daba del "chico bonito" se anunciaba la idea del "parásito de la civilización" que, más tarde, reaparecía en la construcción de la voz de Dr. Antonio. El chico bonito de João do Rio partía del principio de que nadie era honesto, "ejemplarmente honesto del comienzo al fin de la vida", en tierras cariocas. Mandando a la cárcel al ladrón gentleman, el burgués se vengaba de su espejo invertido 4 .

Dos años más tarde, en el folletín del mismo diario, João do Rio publicaba el texto Lo representativo del robo inteligente. Para el cronista, había hombres que eran representativos: un héroe, por ejemplo, era alguien capaz de transmitir un ejemplo de

\footnotetext{
${ }^{45}$ Ídem, p. 5.

${ }^{46}$ Sobre la "cofradía de los mozos bonitos" ver, por ejemplo: Gazeta de Notícias, Río de Janeiro, 9 de noviembre de 1907, p. 1, "A confraria dos moços bonitos. Um novo lançador de impostos. Na pista. Os trucs dos ladrões Up do date. Como eles operam"; A Notícia, Río de Janeiro, 9 y 10 de noviembre de1907, p. 1, "A confraria dos moços bonitos" y Jornal do Brasil, Río de Janeiro, 24 de noviembre de1907, pp. 7-8, "Os moços bonitos".

${ }^{47}$ A Notícia, Río de Janeiro, 11 y 12 de setiembre de 1909, p. 3, "As opiniões de um Moço Bonito" por João do Rio.
} 
virtud con su propia vida. Desde su visión nietzschiana, poco importaba si la actividad en cuestión era considerada del orden del bien o del mal: así como había poetas o políticos representativos, un país debía contar con ladrones y asesinos representativos. Sin embargo, para João do Rio, en el campo delictivo Brasil no tenía hombres representativos, no tenía héroes:

“¿Cómo es posible que un país entre en el concierto de la civilización sin tener un gran ladrón representativo, pero ladrón de verdad, apenas ladrón, campeón de apoderarse de lo ajeno contra la voluntad de su propietario? Y nosotros no teníamos, a no ser quizás Dr. Antonio, que además está para Arsenio Lupin como la Avenida Central está para la línea de los boulevards o para Oxford Street" 48 .

Entre un folletín y otro, el corolario del relato cambió. Ya no parecía necesario migrar a París para construir fama y respeto como delincuente gentleman. Dr. Antonio, el gran ladrón de hoteles, había abierto un camino. ¿Por qué este personaje fue capaz de desafiar la imposibilidad de devenir ladrón célebre en Brasil? ¿Por qué - preguntaba João do Rio- "simpatizamos todos con Arsenio Lupin” y con las historias de Rocambole? El cronista tenía una respuesta para su pregunta: porque el pueblo amaba visceralmente al ladrón que engañaba a los demás sin terminar preso. La fuga de las prisiones era la piedra de toque del delincuente célebre, condición necesaria de su popularidad. Cuando Barreto escribió este texto, Dr. Antonio acababa de ser detenido en Juiz de Fora. Nunca más saldría de la Casa de Detención, pero un año antes de la muerte de Dr. Antonio, João do Rio consideraba su eventual fuga un acto indispensable para los anales de la criminalidad brasilera: "para los verdaderos patriotas, que admiran a sus hombres representativos, si Dr. Antonio no huye, esa prisión es absolutamente penosa"49.

Sin embargo, a diferencia de otros delincuentes célebres del Brasil como Afonso Coelho y Albino Mendes, la fama de Dr. Antonio no estaba atada a ninguna fuga espectacular5o. Su historia parecía atravesada más por la habilidad para nunca ser

\footnotetext{
${ }^{48}$ A Notícia, Río de Janeiro, 19 y 20 de agosto de 1911, p. 3, "O representativo do roubo inteligente" por João do Rio.

${ }^{50}$ Afonso Coelho, conocido como el "Rocambole brasilero" era un estafador que conquistó notable celebridad en la prensa de comienzos del siglo XX, en gran medida por una mítica fuga de 1897. Por su parte, Albino Mendes, el "Arsène Lupin brasileiro", fue un falsificador de billetes contemporáneo de Coelho, cuya gran hazaña consistió en huir de la Casa de Detención de Río, en 1915, usando dinero falso para sobornar a los guardias. Sobre el tratamiento de esos dos delincuentes en la prensa brasilera, ver: OTTONI, Ana Vasconcelos y SANT'ANNA,
} 
detenido infraganti y lograr, muchas veces, ser suelto por la policía y absuelto por los tribunales. Esa destreza había sido tema de aquella crónica de Bilac en la que comentaba una nueva prisión de Maciel y auguraba una rápida libertad. El aura glamorosa que rodeaba al Dr. Antonio de João do Rio estaba presente una década y media antes en la pluma de Bilac:

\begin{abstract}
"Dr. Antonio es el maleante-modelo. Se viste bien. Entra a la prisión con la misma desenvoltura con que se ingresa en un salón. Sabe conversar de política con los políticos, de finanzas con los banqueros, de disciplina militar con los Generales, de moda con las señoras, de sport con los sportmen, de literatura con los hombres de letras. Su conversación es un caleidoscopio en el que pasan, vivamente alumbrados por un espíritu original y fino, todos los conocimientos humanos. iSeñores! iSepan que es hasta un placer dejarse robar por un ladrón tan delicado y tan inteligente!" ${ }^{51 .}$
\end{abstract}

Para Bilac, la celebridad de Dr. Antonio emanaba, más que de alguna habilidad para huir, de su capacidad gestual y retórica para simular y construir una identidad, de su don de rastaquouère, de su camaleónica destreza de advenedizo, de "sus bellas cualidades de gentleman del hurto" ${ }^{2}$. La idea del ladrón caballeresco fue esencial para la posterior fama de este singular delincuente. Entre marzo y abril de 1912, el escritor Elysio de Carvalho, que entonces trabajaba como director del Gabinete de Identificación de la policía, escribió una serie de crónicas sobre la delincuencia carioca en las que recuperaba los conceptos de Olavo Bilac y João do Rio. Inicialmente fueron publicadas en la revista Careta con el seudónimo de Sancho Sanches y, un año después, reunidas en un texto único con el título "historia natural de los malhechores", que salió en el Boletim Policial del Gabinete de Identificación. Una de esas crónicas giraba en torno a la cuestión de la fisonomía de los ladrones y tomaba al caso de Maciel como modelo de "delincuente fraudulento". Su rostro revelaba los trazos de un "ladrón inteligente y astuto", que para Carvalho era un rasgo común a los estafadores y los falsarios53. El examen fisonómico iba ilustrado por cuatro retratos de Dr. Antonio tomados entre 1905 y 1912 :

\footnotetext{
Marilene Antunes, "O crime no Brasil através dos cronistas policiais da imprensa". In: SILVA, Gian Carlo de Melo (org.), Os crimes e a história do Brasil: abordagens possiveis, Maceió, Edufal, 2015, pp. 317-318.

${ }^{51}$ Fantasio [Olavo Bilac], "Chronica", ob. cit., pp. 2-3.

52 Ídem, p. 3.

${ }_{53}$ Careta, Nro. 197, Río de Janeiro, 6 de marzo de 1912, p. 35, "A physionomia dos criminosos" por Sancho Sanches [Elysio de Carvalho].
} 


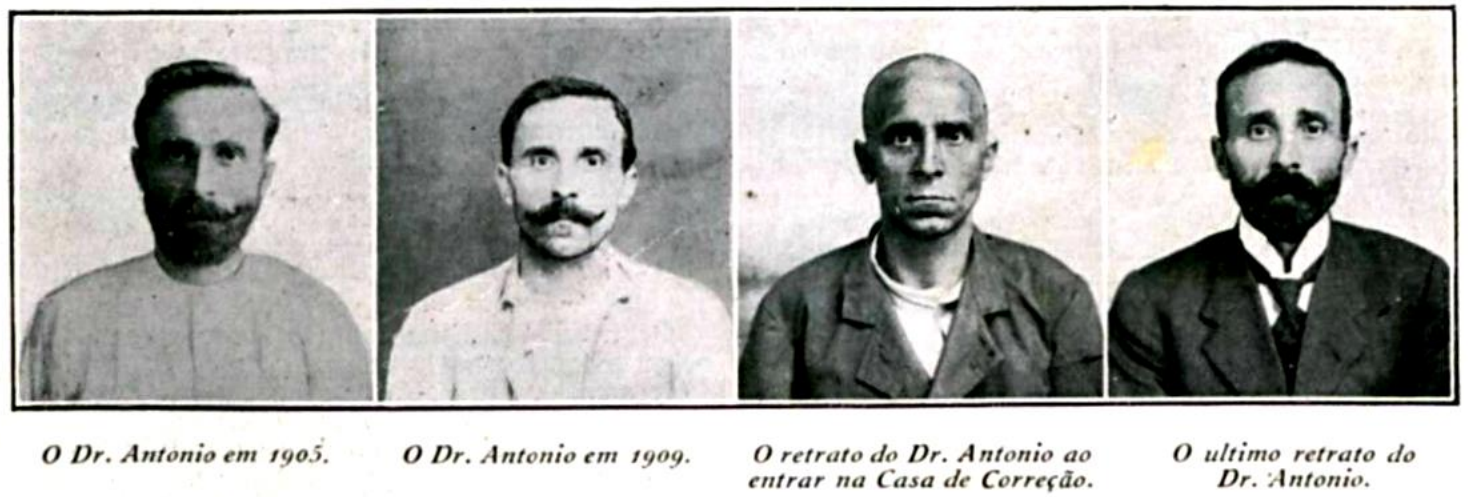

Imagen 3. Retratos de Dr. Antonio. Fuente: Sancho Sanches [Elysio de Carvalho], "A physionomia dos criminosos”, Careta, No. 197, Río de Janeiro, 6 mar. 1912, p. 34.

La revista Careta salía a la calle los días sábados. Una semana después de esta crónica, un nuevo texto de Carvalho incluía una nota aclaratoria: cuando publicaron los cuatro retratos de Dr. Antonio, el sábado 6 de marzo de 1912, los editores de la revista "estaban lejos de suponer que horas después sería un cadáver"54. En efecto, Maciel murió en la Casa de Detención ese mismo sábado, mientras los lectores de Careta -que recién sabrían de su muerte por los diarios del domingo- curioseaban sus retratos. Pocos días después se enterarían que falleció en su propia celda, a las dos y media de la tarde, de un aneurisma de aorta, y que fue enterrado en el cementerio de São Francisco Xavier55.

En la segunda crónica, Carvalho volvía sobre el caso del Dr. Antonio como un ejemplo del delincuente moderno y civilizado: "un tipo como cualquiera de nosotros, vestido con refinada elegancia, frecuentador de buena gente y con las mejores relaciones en el mundo de la Bolsa”. ${ }^{6}$ Un mes después, una tercera crónica de Carvalho hablaba los dos principales ejemplares del delincuente gentleman carioca: Afonso Coelho y Arthur Antunes Maciel, "vulgo Dr. Antonio, fallecido hace algunos días, cuya crónica publicamos en nuestro número anterior" ${ }^{57}$. Cuando Elysio de Carvalho editó este conjunto de crónicas para republicarlas en el Boletim Policial introdujo algunas

\footnotetext{
${ }^{54}$ Careta, Nro. 198, Río de Janeiro, 16 marzo de 1912, p. 18, “A morte do Dr. Antonio”.

55 Noticias sobre la muerte de Dr. Antonio se publicaron en diversos diarios de Río de Janeiro: Gazeta de Notícias, Río de Janeiro, 10 de marzo de 1912, p. 6, "Morte de um rato de hotel” y A Notícia, Río de Janeiro, 11 de marzo de 1912, p. 2, "A morte do Dr. Antonio".

${ }^{56}$ Sancho Sanches [Elysio de Carvalho], “Chronica da gatunice”, Careta, Nro. 198, Río de Janeiro, 16 mar. 1912 , p. 17.

${ }^{57}$ Careta, Nro. 201, Río de Janeiro, 6 de abril de 1912, p. 31, "Dois refinados patifes".
} 
alteraciones textuales. En el trecho recién citado se leía: "vulgo Dr. Antonio, hace tiempo fallecido, cuya crónica fue publicada en libro por uno de nuestros periodistas" 58 . Carvalho no necesitó explicitar que se refería a Barreto: es creíble que el campo literario y periodístico de Río de Janeiro supiera que por detrás de las Memorias estaba la mano de ese cronista. A tan solo un mes de la muerte de Maciel y con la mayor naturalidad, podía leerse en el diario Correio da Manhã: "Paulo Barreto ha recibido muchas felicitaciones por el éxito práctico de su último trabajo, las Memorias de un ratón de hotel" 59 .

Comprender las negociaciones que la Gazeta de Notícias trabó con sus lectores para conseguir el gran fenómeno editorial de las memorias del Dr. Antonio, no es una tarea sencilla. Los indicios sobre esos lectores, sus preferencias, expectativas y prácticas de lectura, distan de ser abundantes. Sin críticas, reseñas, ni cartas de lectores, los avisos publicitarios se tornan un vestigio fundamental para entender la condición de sus posibles consumidores.$^{60}$ En diciembre de 1911, con Maciel preso y condenado por un robo en la Pensión Verdi de la calle Catete, la Gazeta de Notícias comenzó a difundir el advenimiento de las Memorias. La estrategia comercial incluyó anuncios publicitarios en distintos diarios de la capital:
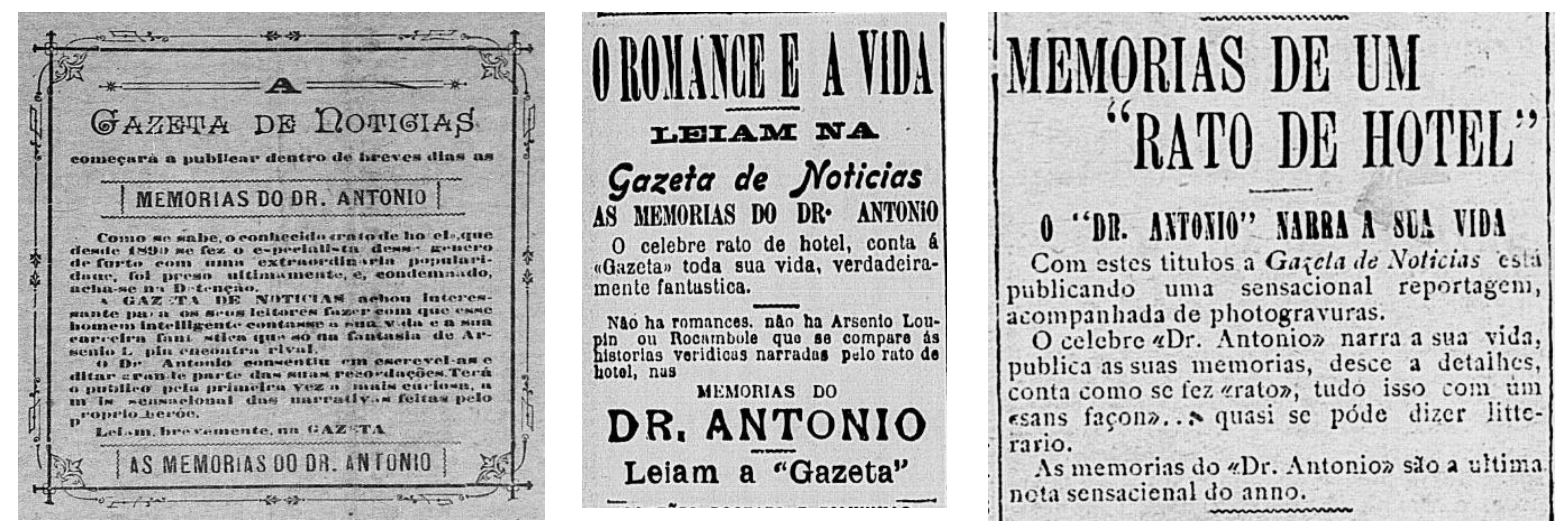

Imagen 4: anuncios publicitarios anunciando las Memórias de um rato de hotel. Fuentes (de izquierda a derecha): Gazeta de Notícias, 22 dic. 1911, p. 1; Correio da Manhã, 29 de diciembre de 1911, p. 12; A

Notícia, 31 de diciembre de 1911, p. 1.

\footnotetext{
${ }^{58}$ Boletim Policial, año VII, Nro. 4, Río de Janeiro, abril de 1913, p. 61, "História natural dos malfeitores. Notas e crônicas" por Eysio de Carvalho.

${ }^{59}$ Correio da Manhã, Río de Janeiro, 12 de abril de 1912, p. 1, "Pingos e respingos".

${ }^{60}$ Sobre la interpretación de los rastros de lectores plebeyos en los anuncios publicitarios ver: SARLO, Beatriz, El imperio de los sentimientos. Narraciones de circulación periódica en la Argentina, 1917-1927, Buenos Aires, Siglo XXI, 2011, pp. 29-56.
} 
Dos elementos llaman la atención en estos anuncios. En primer lugar, las Memorias parecían dirigidas a un público que, además de conocer al "célebre Dr. Antonio", estaba entrenado en la lectura de las novelas folletinescas de Ponson du Terrail y Leblanc. Las aventuras de Rocambole, cuyas traducciones al portugués fueron publicadas en la prensa brasilera desde la década de 1860, y las de Lupin, que inundaron las secciones de folletines a comienzos del siglo XX, eran usadas como punto de referencia para un lector ciertamente más plebeyo que Olavo Bilac, Paulo Barreto y Elysio de Carvalho, quienes accedían a esas obras a través de sus originales en francés. Para esos otros consumidores de ficciones policiales, el diálogo entre texto e imagen parecía ser fundamental. En los avisos que la Gazeta de Notícias publicaba para promocionar los folletines de Lupin, en 1907, se destacaba que los folletines venían acompañados por grabados. Lo mismo sucedía ahora con las publicidades de las memorias de Dr. Antonio.

En segundo lugar, los anuncios enfatizaban el carácter autobiográfico del relato. "La Gazeta de Notícias creyó interesante para sus lectores hacer que ese hombre inteligente contara su vida y su carrera fantástica". La propia empresa periodística explicaba que "Dr. Antonio consintió en escribir y dictar gran parte de sus memorias". En paralelo, numerosos anuncios en el diario A Notícia destacaban que Maciel había "escrito para la Gazeta", "narrando su vida" y que el diario estaba publicando "un sensacional reportaje acompañado de fotograbados". "No hay novela, no hay Lupin ni Rocambole, que se compare con las historias verídicas narradas por el ratón de hotel”, se leía -por último- en una publicidad del Correio da Manhã. ${ }^{61}$ Es decir, en paralelo con la insistencia en el consentimiento del ladrón a narrar su vida, en la afirmación incisiva de la presencia de su voz garantizando una "historia verídica", no se ocultaba a los lectores que tanto podría escribirlas como "dictarlas", que habría un interlocutor (el repórter) y que se trataba, ante todo, de un "sensacional reportaje”. Un día antes de la aparición del primer folletín, Gazeta de Notícias publicó una larga carta del mismísimo Maciel, escrita desde la prisión, en la que el ladrón decía:

\footnotetext{
${ }^{61}$ Gazeta de Notícias", Río de Janeiro, 24 de diciembre de 1911, p. 1, "A Notícia” y Gazeta de Notícias, Río de Janeiro, 28 de diciembre de 1911, p. 1 y Correio da Manhã, Río de Janeiro, 29 de diciembre de 1911, p. 12, “O romance e a vida".
} 
"Excelentísimo. Sr. Redactor de la Gazeta de Notícias - Prontamente y con la mejor voluntad accedí al pedido de la Gazeta, a fin de ofrecer apuntes y escribir acerca de mi pasado. Relaté minuciosamente los hechos y delitos con todas las peripecias [...]. Actualmente estoy preso y condenado por el delito que se dio últimamente en el Hotel Verdi y realmente no contaba con la sentencia condenatoria y, aún peor, con la pena máxima, porque nunca conté con que el honrado Dr. Juez del $1^{\mathrm{o}}$ Tribunal Criminal me condenaría por un delito en el que no hubo flagrante, basándose solo en una confesión mía que fue arrancada por la policía, a fuerza de golpes y martirios de camisa de fuerza. La prueba de lo que vengo a alegar puede ser testimoniada por varias personas que en el momento se encontraban en la $6^{\circ}$ comisaría policial y presenciaron mi declaración al respectivo comisario, de que yo no era autor ni cómplice, ya que mucho antes y después, el día y la noche en que sucedió el delito, me encontraba en San Pablo, declaración que probé convenientemente; y preguntado y repreguntado, insistí en la misma declaración y fui golpeado hasta que perdí mis fuerzas, viéndome en el dilema entre la muerte cierta y la confesión forzada de delito, que me era exigida violentamente por la inquisitorial autoridad policial. [...] Sr. Redactor, espero de su reconocida generosidad hacer publicar esta carta cuando se dé publicidad a las "Memorias del Dr. Antonio", prometidas para el próximo domingo. Es una caridad que usted hará a un infeliz preso y enfermo. Anticipándoles mis agradecimientos, le hago llegar los mejores votos de feliz comienzo para el año. - Arthur Antunes Maciel - Río, Casa de Detención, 22 de diciembre de 1911”62.

Es evidente que este texto formaba parte de la estrategia comercial del diario para publicitar el folletín, pero nada permite dudar de la autenticidad de la carta. Al contrario, ofrece elementos que exceden las intenciones empresariales del diario y permiten pensar por qué Maciel aceptó narrar su vida a un periodista de la Gazeta de Notícias. Condenado y gravemente enfermo (como corroboraría su muerte meses después), las memorias eran un último recurso para generar un clima favorable al habeas corpus por prisión ilegal. La primera entrega del folletín, que salió al día siguiente, narraba el encuentro entre el ladrón y el repórter en la Casa de Detención. Según el relato, al salir de la enfermería de la cárcel, en la que se trataba el "mal del corazón”, el administrador de la cárcel le presentó al periodista que en seguida le declaró la mayor admiración y le pidió que "cuente su vida para mi diario". Ante la primera negativa de Maciel, el repórter insistió hasta lograr un "voy a consultarlo con mi abogado”. En ese punto de la narrativa, Barreto -que jamás reveló su intervención en las Memorias - tomó la decisión de dejar un indicio: al reconstruir la voz del Dr.

\footnotetext{
${ }^{62}$ Gazeta de Notícias, Río de Janeiro, 23 de diciembre de 1911, p. 2, “O Dr. Antonio escreve à Gazeta contra a injustiça da sua última condenação. Rebela-se o rato de hotel”.
} 
Antonio, en unas supuestas meditaciones nocturnas sobre la propuesta de Gazeta de Notícias, le atribuyó al ladrón el recuerdo de "la última vez que fui preso", en agosto de 1911, cuando “un cronista escribió lo siguiente sobre mí”. Y, a continuación, reprodujo gran parte del texto Lo representativo del robo inteligente, de João do Rio. Después de la larga cita, Maciel estaba convencido de escribir las memorias. De esta manera cerraba el primer capítulo con un retorno al diálogo con el repórter:

“- Además, agregó el hombre del diario a la mañana siguiente, usted es nuestro primer

"ratón de hotel". iEs necesario escribir sus memorias!

- Pues escriba.

- ¿Por qué no escribe usted?

- La mano tiembla. Siéntese, que yo dicto"63.

La misma idea que asomaba, con cierta transparencia, en los anuncios publicitarios, volvía ahora en la primera entrega del folletín: las memorias como un texto fabricado a dúo, por un ladrón que "dicta” y un repórter que "redacta”. En Le livre des vies coupables, Philippe Artières estudió diez autobiografías de delincuentes contemporáneas a las memorias de Dr. Antonio, todas ellas producidas por encargo del médico criminalista Alexandre Lacassagne. Además de reconocer a estos textos como resultado del encuentro entre un preso y un intelectual que demanda el registro confesional, Artières se pregunta por qué esos sujetos se aventuran a una práctica de escritura que les resulta completamente ajena a su métier ${ }^{64}$. En paralelo, Dr. Antonio comenzaba su relato revelando que nunca pensó en escribir memorias, ni fue dado a la literatura y que era "muy limitado” el número de libros que había leído. Los motivos que llevaron a Maciel a aceptar la propuesta de Gazeta de Notícias pueden ser diversos y, en parte, insondables: la fragilidad de su salud y de su situación judicial a fines de 1911 quizás hayan sido tan importantes como la propia habilidad de Barreto para convencerlo. Según el relato del encuentro entre ellos en la prisión, Barreto trató de persuadirlo diciendo que sería una desilusión que el ladrón más inteligente del Brasil resolviera negar "lo que está probado en veinte años de diarios"65.

\footnotetext{
${ }^{63}$ Dr. Antonio, Memórias, ob. cit., p. 11-12.

${ }^{64}$ ARTIERES, Philippe, Le livre des vies coupables. Autobiographies de criminels (1896-1909), Paris, Albin Michel, 2000, p. 380.

${ }^{65}$ Dr. Antonio, Memórias, ob. cit., p. 9.
} 
¿Pero, entonces, para qué necesitaba Barreto del testimonio de Maciel si para construir el folletín bastaba con revisar el propio archivo de la Gazeta de Notícias? Una posible respuesta emerge cotejando esas dos décadas de crónicas en la prensa con el texto de las memorias. Por un lado, la estrategia narrativa del folletín requería informaciones que excedían lo conocido por los lectores de las columnas policiales y ese exceso era, precisamente, lo que garantizaba el éxito editorial de las memorias. Es razonable imaginar que en 1911 los lectores quisieran primicias sobre un ladrón al cual, según decía un cronista, "tal vez no haya en toda la ciudad de Río de Janeiro una sola persona que no lo conozca" ${ }^{6}$. En ese sentido, los primeros capítulos sobre la relación con la familia Antunes Maciel en Río Grande do Sul eran centrales, porque al mismo tiempo en que llevaban al lector elementos desconocidos de la vida de Dr. Antonio, fijaban en la trama un giro novelesco: la traición familiar y la huida del hogar como punto de partida de una carrera delictiva. Otra zona en la que el folletín innovaba respecto de lo ya conocido por los lectores de diarios era la vida de Maciel dentro de la prisión. Como vimos antes, y como el propio Dr. Antonio protestaba, la prensa abundaba en detalles sobre sus robos, pero se tornaba opaca a sus años en la Casa de Detención. El relato intimista de los días de prisionero se mezcla, en diversos capítulos, con una crónica sobre la prisión puertas adentro, que marca una cierta distancia del registro autobiográfico, cediendo lugar a la historia de otros ladrones detenidos en el mismo lugar, a interpretaciones de criminología ligera sobre la cárcel como escuela del delito y hasta el ensayo de un diccionario de argot delictivo, que dialogaba explícitamente con la bibliografía policial de la época ${ }^{67}$. Es improbable que el relato de Maciel, quien se confesaba poco lector, haya tenido injerencia en esas páginas en las que Barreto se desplazaba con mayor libertad hacia un terreno conocido: en 1905, como João do Rio, había firmado siete reportajes sobre la Casa de Detención, publicados en la Gazeta de Notícias con el título común En los jardines del crimen ${ }^{68}$. Ese relato de la intimidad de la prisión era reforzado, tanto en el folletín del diario como en el libro, por numerosas fotografías: de la fachada de la Casa de Detención, de la enfermería en la que trataba su malestar Dr. Antonio, de las galerías y puertas

\footnotetext{
${ }^{66}$ O Século, Río de Janeiro, 13 de diciembre de 1911, p. 2, "O Dr. Antonio condenado a treze anos".

${ }^{67}$ Por ejemplo, en el capítulo sobre el argot delictivo se cita el libro de REIS, Vicente, Os ladrões no Rio, 18981903, Río de Janeiro, Laemmert, 1903.

${ }^{68}$ Estas crónicas fueron incluidas, más tarde, en el libro A alma encantadora das ruas (1908). Sobre este reportaje prisional ver: SANT'ANNA, Marilene Antunes, A imaginação do castigo: discursos e práticas sobre a Casa de Correção do Rio de Janeiro, Río de Janeiro, UFRJ/ IFCS, 2010, pp. 179-183.
} 
internas, e inclusive una producción fotográfica de Maciel escribiendo sus memorias en el despacho de jefe de guardias.

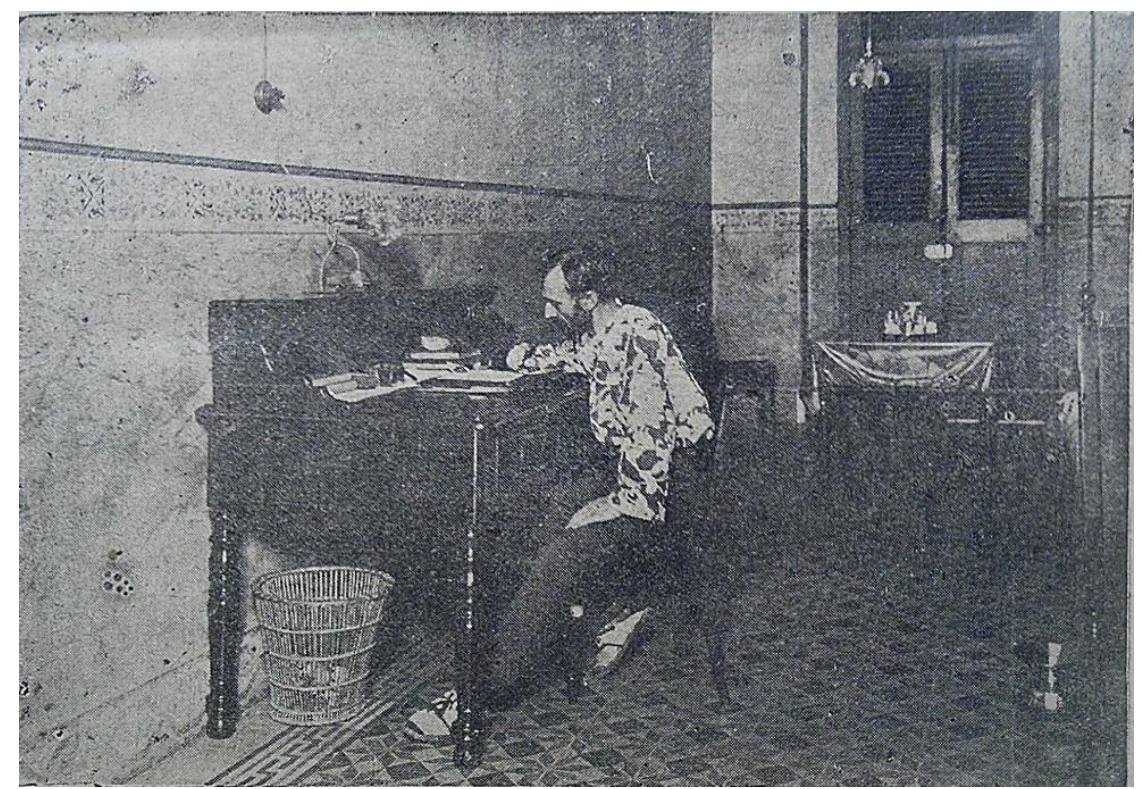

Imagen 5. Memórias de um rato de hotel. A vida de Dr. Antonio narrado por ele mesmo, Río de Janeiro, 1912.

La insistencia en la participación de Maciel en el proceso de escritura de las memorias, recurrente en los anuncios publicitarios y reafirmada por esta fotografía que ilustraba la primera entrega del folletín, formaba parte de la estrategia comercial de la Gazeta de Notícias. Pero los lectores también sabían de la existencia de un repórter por detrás del difundido "reportaje”. Ni el recurso a la estructura novelesca, ni los guiños bibliográficos y eruditos del texto, son suficientes para inclinarnos a situarlo en el opus João do Rio. Ni el Dr. Antonio era una "máscara literaria" de João do Rio, ni tampoco sus memorias eran iniciativa "única y exclusiva" de Paulo Barreto69. Ante todo, Dr. Antonio no era una invención de Barreto, sino del propio Maciel, como queda claro en las crónicas policiales de sus primeros robos. La operación de Barreto consistió, más bien, en convertirlo en un "ratón de hotel", expresión que no aparecía en ninguno de los relatos periodísticos de sus dos décadas de delincuencia. Fue João do Rio, en la crónica Lo representativo del robo inteligente, el que introdujo la idea de una "metamorfosis en rat d'hôtel". El uso del francés en el original es significativo, ya

\footnotetext{
${ }^{69}$ La primera afirmación pertenece a TRAZZI MENDES, Lucas, "As máscaras do crime: o representativo da inteligência e da fatalidade brasileira nas Memórias de um rato de hotel", Antítese, Vol. 6, Nro. 12, 2013, pp. 579580 y la segunda a DALL'AGNOL, Antonio, "História, memória e ficção: o caso Dr. Antônio", Cad. Pesq. Cdhis, Vol. 23, Nro.1, 2010, p. 103.
} 
que ofrece una pista para reconstruir la fuente de esa noción que el escritor carioca utilizó para reinventar la historia de Dr. Antonio: el cuento Le rat d'hôtel publicado en 1904 por el novelista Jean Lorrain, uno de los principales referentes literarios de Barreto, y quien de hecho popularizó ese término en el mundo francés7o.

La transformación del Dr. Antonio en el rat d'hôtel brasilero fue un éxito absoluto. Y gran parte de ese triunfo se debe a la capacidad de Barreto para persuadir a los lectores del carácter verídico de los hechos que se narraban: "estas memorias son una confesión y no una novela", le hacía decir a Maciel al comienzo de uno de los folletines. ${ }^{71}$ Esa "historia de una vida palpitante de interés", como decía una reseña contemporánea, era una novedad para los lectores brasileros: "la primera vez que asistimos a esa confesión sui generis"72. En Brasil, Barreto y la Gazeta de Notícias estaban surcando el propio camino que recorrían.

Del éxito de esta aventura literaria nos quedan algunos indicios importantes. Cuando los primeros diez de los más de cuarenta folletines ya habían sido impresos, noticias periodísticas contaban que en una calle céntrica de Río de Janeiro (Rua do Carmo) circulaban, en "papeles escritos a máquina”, copias piratas del capítulo publicado el día anterior. Ante eso, la Gazeta de Notícias aprovechó para recordar que estaba prohibida la reproducción de las memorias de Dr. Antonio en cualquier otro diario, porque Maciel le había cedido a la empresa en forma exclusiva la "publicación de su confesión"73. El último folletín salió a la calle el 3 de febrero de 1912 y a fines de marzo, poco después de la muerte de Maciel, comenzó la venta de las Memorias, reunidas en un folleto de doscientas páginas, que el lector podía adquirir en la librería Garnier por doscientos reis. Ese precio equivalía a dos veces el costo del diario , lo que resultaba barato para el mercado de libros, si se considera que, en la misma Garnier, los títulos de João do Rio se vendían, en tapa blanda, a tres mil reis. Según la versión de la Gazeta de Notícias se vendieron tres mil ejemplares en las dos primeras

\footnotetext{
${ }^{70}$ Sobre la importancia de Jean Lorrain en la obra de Barreto ver: O’DONNELL, Julia, ob. cit., p. 93 y RODRIGUES, João Carlos, João do Rio: vida, paixão e obra, Río de Janeiro, Civilização Brasileira, 2010 , pp. 85-87.

${ }^{71}$ Dr. Antonio, Memórias, ob. cit., 71.

${ }^{72}$ A Notícia, Río de Janeiro, 12 de enero de 1912, p. 1, "O célebre Dr. Antonio e as suas memórias na Gazeta".

${ }^{73}$ Gazeta de Notícias, Río de Janeiro, 4 de enero de1912, p. 3, “As Memórias do Dr. Antonio”.
} 
semanas ${ }^{74}$. Tan solo en el primer día fueron vendidos trescientos, en lo que parece haber sido una jornada agitada para los empleados y clientes de Garnier: largas filas, aglomeraciones y problemas para enfrentar el robo de libros. A la mañana, un cajero tuvo que correr a un muchacho al que se le encontraron, escondidos entre las páginas de un diario, diez ejemplares de las memorias. La prensa del día siguiente bromeaba: “iParece increíble, Dr. Antonio robado!”75.

\section{Consideraciones finales}

La historia de las Memorias de un ratón de hotel puede separarse en dos fases diferentes. Este artículo se ocupó de la primera etapa, que gira en torno a su producción, circulación y recepción contemporánea entre los lectores que, entre finales del siglo XIX y comienzos del XX, siguieron las crónicas policiales de los robos de Dr. Antonio, presenciaron el fenómeno editorial de los folletines y su muerte precoz. Esa generación conocía su nombre antes de la publicación de las memorias y continuó alimentando el mito del gran ladrón de hoteles brasilero en las décadas siguientes. Por años, las noticias en la prensa acerca de robos en hoteles incluyeron referencias a sus hazañas y esos ladrones eran tratados como "émulos" o “discípulos" del Dr. Antonio76. Otros disentían de esa idea: en 1914, un redactor de la revista Fon-Fon identificado como uno de aquellos contemporáneos que gustaban del delito y simpatizaban con los grandes delincuentes, reclamaba que todos los ladrones cariocas parecían seres inferiores y faltos de imaginación, que "Dr. Antonio, aquel enternecedor ratón de hoteles, no había dejado discípulos"77. Cuando, en 1925, la revista Vida Policial republicó las Memorias tuvo poca necesidad de explicar a sus lectores quién era Dr. Antonio. Un dibujo del ilustrador Cícero Valladares encabezó cada uno de los folletines: Maciel aparecía en la Casa de Detención, trajeado a lo ladrón gentleman y escribiendo sus memorias. Una vez más, como en la propuesta de Gazeta de Notícias, el proyecto gráfico que acompañaba al folletín destacaba la figura del ladrón escritor78.

\footnotetext{
${ }^{74}$ Gazeta de Notícias, Río de Janeiro, 27 de marzo 1912, p. 2, “O Dr. Antonio e suas memórias novamente em foco" y Gazeta de Notícias, Río de Janeiro, 11 de abril de 1912, p. 3, “As memórias do Dr. Antonio".

75 A Notícia, Río de Janeiro, 3 de abril de 1912, p. 1, "Dr. Antonio roubado".

${ }^{76}$ GALEANO, Diego. Criminosos viajantes: circulações transnacionais entre Rio de Janeiro e Buenos Aires, 1890-1930, Río de Janeiro, Arquivo Nacional, 2016, pp. 191-193.

${ }^{77}$ Fon-Fon, Nro.30, Río de Janeiro, 25 de julio de1914, p. 27, "A vida mundana"

${ }^{78}$ Vida Policial, año 1, Nro. 2, Río de Janeiro, 21 de marzo de 1925, pp. 23-32, "Memórias de um rato de hotel”.
} 
Todavía en la década de 1930, ante la aparición de otro ladrón de apodo Dr. Antonio, el Jornal do Brasil aclaraba que no era el mismo "ratón de hotel que tanto trabajo dio a las autoridades", sino de un émulo, una "segunda edición mejorada y aumentada"79. Pero esa memoria de lectura y ese mito urbano del Dr. Antonio, en algún momento a mediados del siglo XX, se esfumaron. Sin la fuerza que tuvo a comienzos de siglo, el frágil librito de tapas blandas fue convirtiéndose en alimento de las termitas y descartado de bibliotecas, hasta que no quedaron más que tres o cuatro ejemplares localizables de los miles que habían sido vendidos. Uno de ellos fue encontrado en una librería de usados de Río de Janeiro por el bibliófilo Plínio Doyle y comprado, en ese momento, por la módica suma de dos cruzeiros. Lo que llamó la atención del coleccionista (poco afecto a la literatura policial) fue que en la segunda página había una anotación de su antiguo dueño que decía: "el autor de este libro es João do Rio". Doyle contó esa historia en una nota previa a la reedición de las Memorias, firmada en octubre de 2000, al cumplir 94 años ${ }^{80}$. Un mes después murió y su ejemplar se conserva, junto a su biblioteca, en la Fundación Casa de Rui Barbosa.

Esta reedición del año 2000 inauguró, así, una segunda fase en la historia de las Memorias. Y lo hizo de una manera tan singular como paradójica: por un lado, el copyright del libro fue registrado con la autoría de "Arthur Antunes Maciel (18651912)", lo que no existía en la edición original, y, por el otro, se empeñaba en demostrar la autoría de "João do Rio" lo que quedó en manos de un post scriptum del principal biógrafo de Paulo Barreto, João Carlos Rodrigues. En la misma edición se incluyó el artículo de João do Rio Lo representativo del robo inteligente, que Rodrigues usó para argumentar en favor de la autoría de Barreto, ejercicio que repitió en su biografía. ${ }^{81} \mathrm{El}$ "misterio literario" de la autoría - según la expresión usada por los editores- no tenía nada de misterioso para sus contemporáneos.

El hallazgo de Plínio Doyle y su empeño para reeditar el libro renovaron el interés por la historia de Dr. Antonio, que no solo volvió a ganar espacio en la prensa brasilera, sino también una obra de teatro (Memórias de um rato), que se estrenó en 2009 en el teatro Casa da Glória y que se anunciaba como una "adaptación de las

\footnotetext{
79 Jornal do Brasil, Río de Janeiro, 6 de mayo de 1932, p. 11, "Mais uma proeza do Dr. Antonio".

${ }^{80}$ DOYLE, Plínio. "Nota previa", In MACIEL, Arthur Antunes, Memórias de um rato de hotel, Río de Janeiro, Dantes, 2000, pp. 9-13.

${ }^{81}$ RODRIGUES, João Carlos, ob. cit., pp. 143-148.
} 
memorias de Dr. Antonio, autor anónimo, supuestamente João do Rio”. Por último, en 2015 hubo una tercera edición, más lujosa, y se estrenó en Brasil un largometraje sobre la vida de Maciel, dirigido por Mini Kerti, cuyo título parafraseaba uno de los capítulos de las Memorias: "Muchos hombres en uno solo". Todo este renacimiento cultural de las memorias de Dr. Antonio tuvo como correlato el surgimiento de algunos trabajos monográficos dedicados al tema ${ }^{82}$. En gran medida, esos trabajos quedaron atrapados en torno de la pregunta de Doyle sobre la cuestión de la autoría.

Lo que en este artículo intentamos responder es hasta qué punto esa pregunta era relevante para los lectores contemporáneos del folletín. Ese problema nos llevó a una indagación sobre las pistas de los sentidos que esos lectores le atribuían a la propuesta de la Gazeta de Notícias, reflejados en la manera en que los avisos publicitarios y el texto de las propias memorias construían un cierto pacto ficcional. Vimos que la insistencia en la figura del ladrón narrador, que escribe o "dicta", no era incompatible con el reconocimiento de la figura de un repórter que entra a la prisión, convence al detenido y, si hay un trabajo de "dictado", por definición quiere decir que hay alguien más que escucha, registra y escribe lo que otro dicta. Nada de eso era ocultado a los lectores, salvo el nombre del repórter.

En 1918, un diario en el que Paulo Barreto participaba como una especie de jefe de redacción, el Rio-Jornal, publicó las memorias del falsificador Albino Mendes, célebre por una espectacular fuga ocurrida tres años antes. Cuando el folletín salió a la calle, un redactor del más tradicional diario $O$ Paiz cuestionaba lo que ya veía como una tendencia a la "colaboración de delincuentes célebres" en la actividad periodística. La crítica no apuntaba tanto a la calidad de los textos, ni tampoco mencionaba el problema de la autoría: el eje pasaba por la cuestión de la veracidad y la autenticidad de los relatos. Exigía que esos folletines fueran tratados como lo que creía que eran: "obras de ficción", basadas en el "simple mecanismo de la fabulación", piezas de literatura que "carecían de realidad"83. Este cuestionamiento apuntaba al corazón del axioma que vertebraba el éxito de esas lecturas. Sea cual fuere el papel del repórter en confección del producto final, el relato debía ser verídico y verosímil.

\footnotetext{
${ }^{82}$ DALL'AGNOL, Jury, ob. cit., y TRAZZI MENDES, Lucas, ob. cit.

${ }^{83}$ O Paiz, Río de Janeiro, 21 de abril de 1918, p. 1, “A Semana” por Oscar Lopes.
} 
Verídico, en el sentido de ser capaz de captar aquello que los lectores, que veían siguiendo las crónicas policiales de la prensa, identificaban como la verdad sobre Dr. Antonio. Pero también debía ser verosímil y, por lo tanto, la novelización del relato tenía sus límites. João do Rio podía desear en 1911, como vimos, que Maciel se escapara de su última prisión, porque una fuga le daría a su historia un giro definitivamente atractivo para los lectores. Pero, a fines de ese mismo año, el repórter Barreto no pudo inventar esa fuga como un capítulo de las memorias de Dr. Antonio. Sus lectores no esperaban ficción, sino realidad, y sabían que Maciel nunca se había fugado. Las Memorias están llenas de episodios incomprobables, donde es posible que la pluma de Barreto se haya deslizado con numerosas libertades, pero siempre tomó el cuidado de hacerlo sobre las regiones desconocidas de la vida de ladrón de hoteles. Tan solo en los huecos que dejaba lo real (lo que los lectores entendían por realidad) la ficción podía hacerse un lugar, tornando a las memorias literatura.

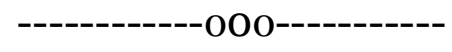

\section{Bibliografía}

ARTIERES, Philippe, Le livre des vies coupables. Autobiographies de criminels (18961909), Paris, Albin Michel, 2000.

BARBOSA, Marialva, História cultural da imprensa Brasil, 190o-20oo, Río de Janeiro, Mauad, 2007.

BUFFINGTON, Robert; PICCATO, Pablo, "Crime stories". In: BUFFINGTON, Robert; PICCATO, Pablo, True Stories of Crime in Modern Mexico, Albuquerque, University of New Mexico Press, 2009.

CAIMARI, Lila, Apenas un delincuente. Crimen, castigo y cultura en la Argentina, 1880-1955, Buenos Aires, Siglo XXI, 2004.

CHAZKEL, Amy, "Uma perigosíssima lição: a Casa de Detenção do Rio de Janeiro na Primeira República”. In: MAIA, Clarissa Nunes; NETO, Flávio de Sá; COSTA, Marcos y BRETAS, Marcos Luiz (org.), História das Prisões no Brasil, Vol. 2, Río de Janeiro, Rocco, 2009. 
DALL'AGNOL, Antonio, “História, memória e ficção: o caso Dr. Antônio”, Cad. Pesq. Cdhis, Vol. 23, $\mathrm{n}^{\circ}$ 1, 2010.

DIMAS, Antonio (ed.), Bilac, o Jornalista. Crônicas. Vol. I, San Pablo, Edusp/Unicamp, 2006.

DOYLE, Plínio. “Nota previa”, In MACIEL, Arthur Antunes, Memórias de um rato de hotel, Río de Janeiro, Dantes, 2000.

Dr. Antonio, Memórias de um rato de hotel. A vida de Dr. Antonio narrado por ele mesmo, Rio de Janeiro, 1912.

GALEANO, Diego. Criminosos viajantes: circulações transnacionais entre Rio de Janeiro e Buenos Aires, 189o-1930, Río de Janeiro, Arquivo Nacional, 2016.

GILL, Rubén. “O Século Boêmio”, Dom Casmurro, $\mathrm{n}^{\circ}$ 318, Río de Janeiro, 11 de setiembre de 1943 .

KALIFA, Dominique, L'encre et le sang. Récits et société à la Belle Époque, Paris, Fayard, 1995.

LEBLANC, Maurice. Arsênio Lupin, ladrão de casaca. Trad. João Távora. Río de Janeiro: Casa Editora Vecchi, 1952.

O’DONNELL, Julia, De olho na rua. A cidade de João do Rio, Rio de Janeiro, Zahar, 2008.

PEREIRA, Leonardo, "Negociações impressas: a imprensa comercial e o lazer dos trabalhadores no Rio de Janeiro da Primeira República”. Revista História, San Pablo, UNESP, Vol. 35, 2016.

OTTONI, Ana Vasconcelos y SANT'ANNA, Marilene Antunes, "O crime no Brasil através dos cronistas policiais da imprensa”. In: SILVA, Gian Carlo de Melo (org.), Os crimes e a história do Brasil: abordagens possíveis, Maceió, Edufal, 2015 .

REIS, Vicente, Os ladrões no Rio, 1898-1903, Rio de Janeiro, Laemmert, 1903.

RODRIGUES, João Carlos, João do Rio: catálogo bibliográfico, Rio de Janeiro, Secretaria Municipal de Cultura, 1994.

RODRIGUES, João Carlos, João do Rio: vida, paixão e obra, Rio de Janeiro, Civilização Brasileira, 2010.

SAÍTTA, Sylvia, Regueros de tinta. El diario Crítica en la década de 1920, Buenos Aires, Sudamericana, 1998.

SANT'ANNA, Marilene Antunes, A imaginação do castigo: discursos e práticas sobre a Casa de Correção do Rio de Janeiro, Río de Janeiro, UFRJ/ IFCS, 2010. 
SARLO, Beatriz, El imperio de los sentimientos. Narraciones de circulación periódica en la Argentina, 1917-1927, Buenos Aires, Siglo XXI, 2011

TAUNAY, Visconde de, O Encilhamento: cenas contemporâneas da Bolsa do Rio de Janeiro em 189o, 1891 e 1892, San Pablo, Melhoramentos, 1923.

TRAZZI MENDES, Lucas, “As máscaras do crime: o representativo da inteligência e da fatalidade brasileira nas Memórias de um rato de hotel”, Antítese, Vol. 6, n 12 , 2013.

\section{Fuentes}

Archivo Nacional de Brasil - Acervo Judicial:

- Fondo Corte de Apelação, Proc. Nro. 199, caja 1 (1895).

- Fondo Corte de Apelação, Proc. Nro. 113, caixa 1841 (1904).

Biblioteca Nacional de Brasil - Hemeroteca:

- $\quad$ A Cigarra, Río de Janeiro, 1895.

- A Notícia, Río de Janeiro, 1907-1912.

- Almanak Laemmert. Administrativo, mercantil e industrial, Río de Janeiro, 1889-1897.

- Boletim Policial, Río de Janeiro, 1913.

- Careta, Río de Janeiro, 1912.

- Cidade do Rio, Río de Janeiro, 1890-1896.

- Correio da Manhã, Río de Janeiro, 1911-1912.

- Diário do Comércio, Río de Janeiro, 1892.

- Diário de Notícias, Río de Janeiro, 1890.

- Fon-Fon, Río de Janeiro, 1914.

- Gazeta de Notícias, Río de Janeiro, 1890-1912.

- Gazeta da Tarde, Río de Janeiro, 1892-1895.

- Jornal do Brasil, Río de Janeiro, 1890-1907.

- Jornal do Comércio, Río de Janeiro, 1890-1895.

- O Combate, Río de Janeiro, 1892.

- O Cruzeiro. Orgão do Partido Catholico, Río de Janeiro, 1890.

- O Paiz, Río de Janeiro, 1896-1918.

- O Século, Río de Janeiro, 1911.

- Vida Policial, Río de Janeiro, 1925. 